\title{
Meiosis I chromosome segregation is established through regulation of microtubule-kinetochore interactions
}

\author{
Matthew P Miller ${ }^{1 \dagger}$, Elçin Ünal ${ }^{1 \dagger}$, Gloria A Brar², Angelika Amon ${ }^{1 \star}$ \\ ${ }^{1}$ Department of Biology, Massachusetts Institute of Technology, Cambridge, United \\ States; ${ }^{2}$ Department of Cellular and Molecular Pharmacology, University of California, \\ San Francisco, San Francisco, United States
}

\begin{abstract}
During meiosis, a single round of DNA replication is followed by two consecutive rounds of nuclear divisions called meiosis I and meiosis II. In meiosis I, homologous chromosomes segregate, while sister chromatids remain together. Determining how this unusual chromosome segregation behavior is established is central to understanding germ cell development. Here we show that preventing microtubule-kinetochore interactions during premeiotic $\mathrm{S}$ phase and prophase I is essential for establishing the meiosis I chromosome segregation pattern. Premature interactions of kinetochores with microtubules transform meiosis I into a mitosis-like division by disrupting two key meiosis I events: coorientation of sister kinetochores and protection of centromeric cohesin removal from chromosomes. Furthermore we find that restricting outer kinetochore assembly contributes to preventing premature engagement of microtubules with kinetochores. We propose that inhibition of microtubule-kinetochore interactions during premeiotic $S$ phase and prophase I is central to establishing the unique meiosis I chromosome segregation pattern.
\end{abstract}

DOI: 10.7554/eLife.00117.001

*For correspondence: angelika@mit.edu

†These authors contributed equally to this work

Competing interests: The authors have declared that no competing interests exist

Funding: See page 28

Received: 31 July 2012

Accepted: 18 October 2012

Published: 18 December 2012

Reviewing editor:

Michael Botchan, University of California-Berkeley, United States

(c) Copyright Miller et al. This article is distributed under the terms of the Creative Commons Attribution License, which permits unrestricted use and redistribution provided that the original author and source are credited.

\section{Introduction}

Cells have evolved intricate mechanisms to execute proper partitioning of the genetic material during cell division. This task is especially complex in meiosis, the cell division used by sexually reproducing organisms to generate gametes. The goal of meiosis is to reduce the genome content by half such that proper ploidy is maintained upon fusion of gametes. To achieve this, a single round of DNA replication is followed by two consecutive rounds of nuclear division called meiosis I and meiosis II. During meiosis I homologous chromosomes segregate. Meiosis II resembles mitosis in that sister chromatids segregate from each other. The establishment of this specialized chromosome segregation pattern requires three changes that modulate how chromosomes interact with each other and with the microtubule cytoskeleton: (1) reciprocal recombination between homologous chromosomes, (2) the way linkages between sister chromatids, known as sister-chromatid cohesion, are removed from chromosomes and (3) the manner in which chromosomes attach to the meiotic spindle.

Homologous recombination is initiated by programmed double-strand breaks (DSBs), which are catalyzed by Spo11 following premeiotic DNA replication (Keeney et al., 1997). Subsequent repair of DSBs by crossover recombination generates physical linkages between homologous chromosomes. This, in turn, allows homologs to attach to the meiosis I spindle such that each homolog interacts with microtubules emanating from opposite spindle poles. As a result, homologous chromosomes biorient on the meiosis I spindle. The spindle assembly checkpoint prevents the onset of chromosome segregation until this process is completed. Once each pair of homologs is bioriented, checkpoint signaling ceases and anaphase entry ensues. A ubiquitin ligase known as the anaphase promoting complex/cyclosome 
eLife digest Diploid organisms contain two sets of chromosomes, one set inherited from the mother and the other from the father. Humans, for example, have 23 pairs of chromosomes, and the chromosomes within each pair are said to be homologous because they are similar to each other in a number of ways, including length and shape. When it comes time for one of these cells to duplicate, each chromosome is first replicated to generate a pair of identical chromosomes called sister chromatids, which subsequently separate in a cell division process known as mitosis to produce two identical daughter cells.

While most cells proliferate via mitotic cell division, the germ cells that generate gametes in the form of sperm or eggs undergo a different cell division known as meiosis. This process reduces the number of chromosomes by a factor of two, so that the original number of chromosomes is restored by the fusion of gametes during sexual reproduction. During meiotic cell division, a single round of DNA replication is followed by two consecutive rounds of nuclear division called meiosis I and meiosis II. During meiosis I, homologous chromosomes are separated. Subsequently, during meiosis II, the sister chromatids separate to produce a total of four products, each with half the number of chromosomes as the original cell.

The separation of homologous chromosomes or sister chromatids relies on them being pulled apart by microtubules. One end of each microtubule is attached to a protein-based structure called a kinetochore, which is assembled onto the centromere of each chromosome. The other end of each microtubule is attached to a structure that is called a centrosome in human cells and a spindle pole body in yeast cells. Human cells have two centrosomes, which reside on the opposite poles of the cell, and likewise for the spindle pole bodies in yeast cells. In mitotic cells and in meiosis II, microtubules attach to kinetochores in a way that means the sister chromatids are pulled apart. During meiosis I, on the other hand, they attach to kinetochores in a manner so the homologous chromosomes are pulled apart.

Miller et al. now show how the timing of the interaction between the kinetochore and microtubules is critical to ensure that the homologous chromosomes are separated during meiosis I. They found that premature interactions resulted in the separation of sister chromatids (as happens in mitosis) rather than the separation of homologous chromosomes, as is supposed to happen in meiosis I. They also showed that cells prevent such premature interactions by dismantling the outer regions of the kinetochore and reducing the levels of enzymes called CDKs in the cell. These results demonstrate that preventing premature microtubule-kinetochore interactions is essential for establishing a meiosis I-specific chromosome architecture, and they also provide fresh insights into how the molecular machinery that is responsible for mitotic chromosome segregation can be modulated to achieve meiosis.

DOI: 10.7554/eLife.00117.002

and its specificity factor Cdc20 (APC/C-Cdc20) targets Securin for degradation, relieving Separase inhibition (Cohen-Fix et al., 1996; Ciosk et al., 1998). Separase is a protease that cleaves the kleisin subunit of cohesin, the protein complex that mediates sister-chromatid cohesion (Uh/mann et al., 1999, 2000; Schleiffer et al., 2003). In meiosis I, cleavage of cohesin at chromosome arms allows homologs to segregate (Buonomo et al., 2000). However, cohesin around the centromeres is protected from cleavage during meiosis I, which is essential for the accurate segregation of sister chromatids during meiosis II. Protection of centromeric cohesin is accomplished by preventing phosphorylation of Rec8, the meiosis-specific kleisin. This occurs, at least in part, by Sgo1 (MEl-S332)dependent recruitment of the protein phosphatase PP2A to centromeric regions where it antagonizes Rec8 phosphorylation (Kerrebrock et al., 1995; Katis et al., 2004a; Kitajima et al., 2004, 2006; Riedel et al., 2006).

The third modification necessary to bring about the meiotic chromosome segregation pattern is the manner in which kinetochores attach to microtubules during meiosis I and meiosis II. In meiosis I, kinetochores of sister chromatid pairs (henceforth sister kinetochores) attach to microtubules emanating from the same spindle pole, a process called sister kinetochore coorientation. During meiosis II, as during mitosis, sister kinetochores attach to microtubules emanating from opposite spindle poles and are thus bioriented (reviewed in Marston and Amon, 2004). In budding yeast, sister kinetochore 
coorientation is brought about by the monopolin complex, which consists of Mam1, Lrs4, Csm1 and the casein kinase 1, Hrr25 (Toth et al., 2000; Rabitsch et al., 2003; Petronczki et al., 2006). Lrs4 and Csm1 localize to the nucleolus during interphase. During exit from pachytene, a stage of prophase I, Lrs4 and Csm1 associate with Mam1 and Hrr25 at kinetochores, a process that requires the Polo kinase Cdc5 (Clyne et al., 2003; Lee and Amon, 2003; Matos et al., 2008). How the association of monopolin with kinetochores is coordinated with respect to kinetochore assembly and microtubule-kinetochore interactions during meiosis is not understood.

Cyclin-dependent kinases (CDKs) are the central regulators of the mitotic and meiotic divisions. In budding yeast, a single CDK associates with one of six B-type cyclins (Clb1-Clb6) (reviewed in Morgan, 1997). In meiosis, Clb5- and Clb6-CDKs drive DNA replication and recombination, whereas Clb1-, Clb3- and Clb4-CDKs promote the meiotic nuclear divisions (reviewed in Marston and Amon, 2004). Meiotic cyclin-CDK activity is regulated both at the transcriptional and translational level (Grandin and Reed, 1993; Carlile and Amon, 2008). Transcription of CLB1, CLB3 and CLB4 occurs only after exit from pachytene (Chu and Herskowitz, 1998); CLB3 is also translationally repressed during meiosis I, thus restricting Clb3-CDK activity to meiosis II (Carlile and Amon, 2008). The major mitotic cyclin, CLB2, is not expressed during meiosis (Grandin and Reed, 1993).

Here we investigate the importance of cyclin-CDK regulation in establishing the meiotic chromosome segregation pattern. We show that expression of a subset of cyclins during premeiotic $\mathrm{S}$ phase and early prophase I, defined as the prophase stages up to exit from pachytene, causes premature microtubule-kinetochore interactions. This, in turn, disrupts both sister kinetochore coorientation and protection of centromeric cohesin during meiosis I, revealing that the temporal control of microtubulekinetochore interactions is essential for meiosis I chromosome morphogenesis. Furthermore, we define the mechanism by which premature microtubule-kinetochore interactions are prevented; through regulation of cyclin-CDK activity and of outer kinetochore assembly. Our results demonstrate that preventing premature microtubule-kinetochore interactions is essential for establishing a meiosis I-specific chromosome architecture and provide critical insights into how the mitotic chromosome segregation machinery is modulated to achieve a meiosis I-specific pattern of chromosome segregation.

\section{Results}

\section{Cyclin expression is sufficient to induce spindle formation and microtubule-kinetochore interactions}

We previously reported that CLB3 expression prior to meiosis I induces a change in the pattern of chromosome segregation such that sister chromatids, instead of homologous chromosomes, segregate during the first nuclear division (Carlile and Amon, 2008). To determine how Clb-CDKs impact meiotic chromosome segregation and whether Clb-CDKs play redundant or specific roles in regulating this process, we examined the consequences of prematurely expressing CLB1, CLB3, CLB4 or CLB5.

In our previous studies we expressed CLB3 from the GAL1-10 promoter driven by an estrogen inducible Gal4-ER fusion (Carlile and Amon, 2008). Expression from the GAL1-10 promoter led to Clb3 accumulation in meiosis I to levels that are comparable to those seen in meiosis II in wild-type cells (Carlile and Amon, 2008). However, estrogen interferes with meiotic progression when added during early stages of sporulation (Figure 1A). To circumvent this problem we utilized the copperinducible CUP1 promoter to drive Clb3 expression. Expression from the CUP1 promoter led to approximately fivefold higher levels of Clb3 protein compared to expression from the GAL1-10 promoter (Figure 1B). To examine the consequences of the two CLB3 constructs on chromosome segregation we used GAL-CLB3 and CUP-CLB3 strains in which one of the two homologs of chromosome III was marked by integrating a tandem array of tetO sequences $\sim 20 \mathrm{~kb}$ from CENIII (heterozygous LEU2-GFP dots). These cells also expressed a tetR-GFP fusion, which allowed visualization of the tetO arrays (Michaelis et al., 1997). The analysis of GFP dot segregation during the first meiotic division revealed that despite the difference in $\mathrm{Clb3}$ protein levels, the extent of sister chromatid segregation in meiosis I was similar between GAL-CLB3 and CUP-CLB3 cells (Figure 1C). This finding indicates that expression of $\mathrm{Clb3}$ from either the CUP1 or GAL1-10 promoter efficiently induces sister chromatid segregation during meiosis I. Furthermore, the timing of when $\mathrm{Clb3}$ is expressed, rather than the amount of $\mathrm{Clb3}$ present, appears to be the primary determinant of this phenotype. Based on this observation and the finding that all four cyclins showed equal expression when produced from the CUP1 promoter (Figure 1D) we utilized the CUP1 promoter for most subsequent analyses. 
A

\begin{tabular}{ccc} 
& \multicolumn{2}{c}{$\%$ sporulated cells } \\
\cline { 2 - 3 } estradiol $(\mathrm{h})$ & wild-type & GAL4.ER \\
0 & 77 & 1 \\
1 & 61 & 4 \\
2 & 73 & 6 \\
3 & 77 & 35 \\
4 & 85 & 59 \\
5 & 84 & 66 \\
6 & 95 & 71 \\
\hline
\end{tabular}

D
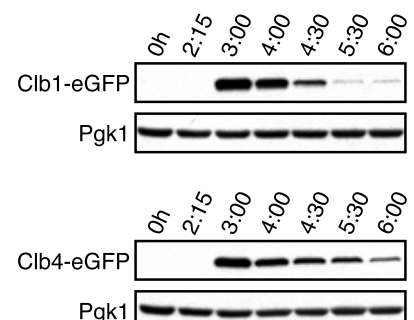

B

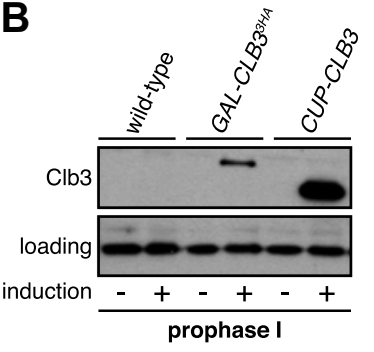

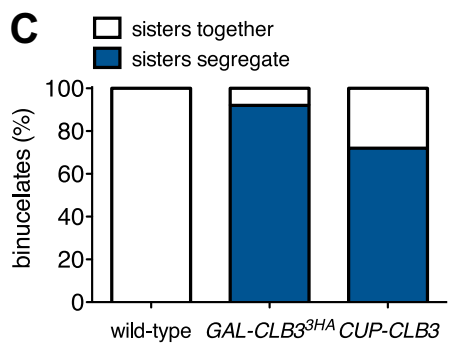

E

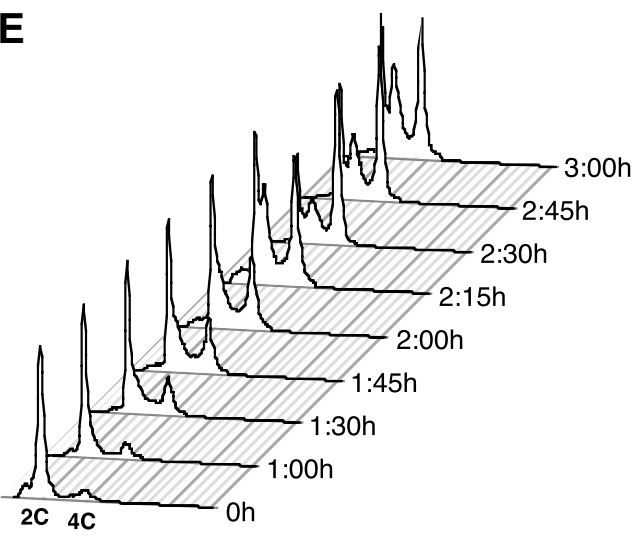

F

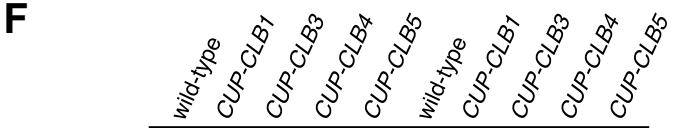

kinase activity

Cdk1 IP

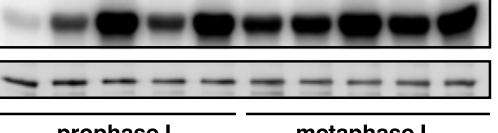

prophase I

metaphase I

anaphase I

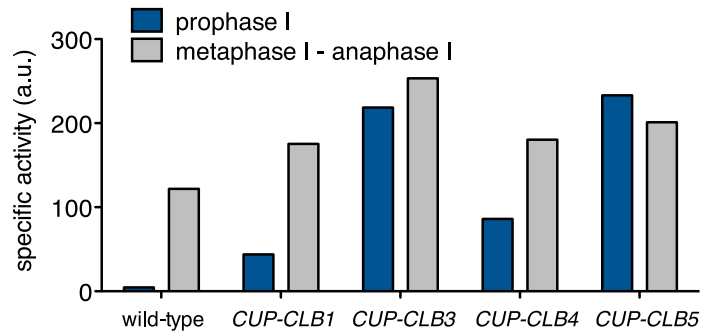

Figure 1. Characterization of premature cyclin expression and corresponding total CDK activity. (A) Wild-type (A4962) and GAL4-ER (A19151) cells were induced to sporulate. At the indicated time points, an aliquot was removed and treated with estradiol ( $1 \mu \mathrm{M})$. The percentage of cells that had sporulated after $24 \mathrm{hr}$ was calculated as the sum of dyads, triads and tetrads divided by the total number of cells ( $\mathrm{n}>100$ cells counted for each condition). (B) Wild-type (A18686), GAL-CLB3-3HA (A23084) and CUP-CLB3 (A23086) cells also carrying the GAL4-ER fusion were induced to sporulate. After 3 hr, CLB3 was induced. Each culture was treated with estradiol $(1 \mu \mathrm{M})$ and $\mathrm{CuSO}_{4}(50 \mu \mathrm{M})$. Cells were harvested after $1 \mathrm{hr}$ of estradiol and $\mathrm{CuSO}_{4}$ treatment for protein extraction. Levels of Clb3 were examined by Western blot analysis. A cross-reacting band was used as a loading reference. (C) Segregation of sister chromatids (equational division) using heterozygous GFP dots integrated at LEU2 ( 20 kb from CENIII) was quantified in binucleate cells from wild-type (A18686), GAL-CLB3-3HA (A23084) and CUP-CLB3 (A23086). Note that the samples were collected from the same experiment described in (B) at a time point when a fraction of the cells had completed meiosis I ( $6 \mathrm{hr} 30 \mathrm{~min}$ and $7 \mathrm{hr}$ after induction of sporulation) ( $\mathrm{n}>100 \mathrm{for}$ each sample). Using a chi-square test ( $\mathrm{df} 1$ ), the fraction of binucleates that display a reductional or equational division was compared between wild-type and GAL-CLB3-3HA $x^{2}=166.4, p<0.0001$ and between wild-type and CUP-CLB3 $x^{2}=108.7, p<0.0001$. (D) Wild-type or CUP-CLB-eGFP cells also carrying the GAL4-ER and GAL-NDT80 fusions were induced to sporulate. After $2 \mathrm{hr} 15 \mathrm{~min}$, cyclins were induced by addition of $\mathrm{CuSO}_{4}(50 \mu \mathrm{M})$. Cells were released from the NDT80 block at $4 \mathrm{hr} 30$ min post transfer to sporulation medium. Cyclin levels monitored by Western blot at the indicated time points in CUP-CLB1-eGFP (A28531), CUP-CLB3-eGFP (A28533), CUP-CLB4-eGFP (A28535) and CUP-CLB5-eGFP (A33199) cells. Pgk1 was used as a loading control. (E) Wild-type (A22678) cells carrying the GAL4-ER and GAL-NDT80 fusions were induced to sporulate and CuSO $(50 \mu \mathrm{M})$ was added $2 \mathrm{hr} 15 \mathrm{~min}$ after transfer into sporulation medium. Samples were taken at indicated time points to determine DNA content by flow cytometry. By 2 hr 15 min $43 \%$ of cells had a 4C DNA content. (F) Left: Wild-type (A28663), CUP-CLB1 (A28665), CUP-CLB3 (A28667), CUP-CLB4 (A28669) and CUP-CLB5 (A28671) cells carrying the GAL4-ER and GAL-NDT80 fusions were induced to sporulate and $\mathrm{CuSO}_{4}(50 \mu \mathrm{M})$ was added $2 \mathrm{hr} 30$ min after transfer into sporulation medium. In vitro kinase assays were performed with Cdc28-3V5 (Cdk1) immunoprecipitated from prophase I samples (collected 4 hr 30 min after sporulation induction, at the time of NDT80 block-release) and metaphase l-anaphase I samples (collected $1 \mathrm{hr} 30 \mathrm{~min}$ after release from the NDT80 block) Right: specific activity was calculated by normalizing the amount of phosphorylated Histone $\mathrm{H} 1$ to the amount of immunoprecipitated Cdc28-3V5 using ImageQuant software (Molecular Dynamics, Sunnyvale, CA).

DOI: 10.7554/eLife.00117.003 
Having established a system to effectively express various cyclins prior to meiosis I we next examined the consequences of their premature expression on meiosis I events. We first asked whether misexpression of various cyclins is sufficient to induce spindle formation in cells arrested in pachytene of prophase I, due to lack of the transcription factor Ndt80 (Xu et al., 1995; Chu and Herskowitz, 1998). We induced cyclin expression from the CUP1 promoter $135 \mathrm{~min}$ after the induction of sporulation when typically $40-65 \%$ of the cells have replicated their DNA (Figure 1E; Blitzblau et al., 2012) and examined spindle pole body (SPB, centrosome equivalent in budding yeast) separation and spindle morphology following induction. As expected, wild-type cells did not form spindles in the absence of NDT80 function. Expression of CLB5 from the CUP1 promoter did not lead to SPB separation and spindle formation either, although expression of CLB5 in the prophase I arrest led to a significant increase in total CDK activity (Figures $1 F$ and 2A, Figure 2-figure supplement 1). In contrast, CUP-CLB1, CUP-CLB3 and CUP-CLB4 cells separated SPBs and formed bipolar spindles, shortly after copper addition (Figure 2A and Figure 2-figure supplement 1). Similar results were observed in cells with intact NDT80 (data not shown). We conclude that expression of CLB1, CLB3 or CLB4 is sufficient to promote bipolar spindle assembly in NDT80-depleted cells.

Next, we determined whether expression of CLB1, CLB3 or CLB4 in pachytene-arrested cells also affects the manner in which chromosomes attach to the meiotic spindle using live-cell imaging. To this end we used strains carrying heterozygous CENV-GFP dots and an Spc42-mCherry fusion (Spc42 is an SPB component) to monitor the behavior of the marked centromere with respect to the spindle axis. In wild-type and CUP-CLB5 cells, sister kinetochores remained closely associated with each other and did not appear to be tightly associated with SPBs, consistent with the observation that these cells failed to form a spindle. In contrast, we observed dynamic separation of heterozygous CENV-GFP dots upon expression of CLB1 or CLB3, with sister kinetochores frequently splitting and coming together (Figure 2B,C). This observation is reminiscent of the behavior of bioriented sister chromatids during metaphase of mitosis (Pearson et al., 2001).

Cells expressing CLB4 did not show transient splitting of sister kinetochores in prophase I, indicating that chromosomes are either unable to attach to the spindle or that homologous chromosomes, instead of sister chromatids, are bioriented as occurs in wild-type cells during metaphase I. To distinguish between these possibilities, we examined the behavior of CUP-CLB4 cells in which both homologs of chromosome V harbor CENV-GFP dots (henceforth homozygous CENV-GFP dots). Similar to wild-type, we observed that in CUP-CLB4 cells the two CENV-GFP dots remained tightly associated in prophase I, indicating that the homologous chromosomes are paired and not attached to the prematurely formed spindle (Figure 2-figure supplement 2). Together, these results indicate that CUP-CLB1, CUP-CLB3 or CUP-CLB4 expression promotes bipolar spindle formation in pachytenearrested cells, but only CLB1 and CLB3 expression can promote stable microtubule-kinetochore attachments sufficient to generate tension.

To determine whether different amounts of total CDK activity were responsible for the phenotypic differences of prematurely expressing $\mathrm{Clb} 1$ or $\mathrm{Clb} 3$ compared to $\mathrm{Clb} 4$, we measured total CDK activity ( $\mathrm{Cdc} 28$ in budding yeast) using Histone $\mathrm{H} 1$ as a substrate. Cdc28-associated kinase activity was low during prophase I and increased more than 25 -fold during metaphase I/anaphase I in wild-type cells (Figure 1F). Expression of all four cyclins led to a significant increase in total CDK activity in prophase I (Figure 1F), but importantly, the degree of increase did not correlate with the ability to induce sister chromatid splitting in the NDT80 arrest. For example, Clb1 expression led to a similar increase in Cdc28associated kinase activity as expression of $\mathrm{Clb} 4$, yet $\mathrm{Clb} 1$ induced sister chromatid splitting whereas $\mathrm{Clb} 4$ did not (Figures $1 \mathrm{~F}$ and $2 \mathrm{~B}, \mathrm{C}$ ). We conclude that the ability to induce sister chromatid splitting does not correlate with total CDK activity produced by the various CUP-CLB fusions. Furthermore, SPB separation and spindle formation are not sufficient to induce microtubule-kinetochore interactions. Events that can be triggered by $\mathrm{Clb} 1$ and $\mathrm{Clb} 3$, but not $\mathrm{Clb} 4$ are also necessary to promote attachments sufficient to generate tension. Determining why CLB4 expressing cells fail to form productive microtubule-kinetochore interactions could provide important insights into substrate specificity of cyclin-CDK complexes.

\section{Expression of CLB3 or CLB1 during premeiotic S phase/prophase I causes sister chromatids to segregate during meiosis I}

To determine the consequences of premature cyclin expression on meiosis I chromosome segregation, we examined the segregation of heterozygous CENV-GFP dots in cells that were reversibly arrested in 

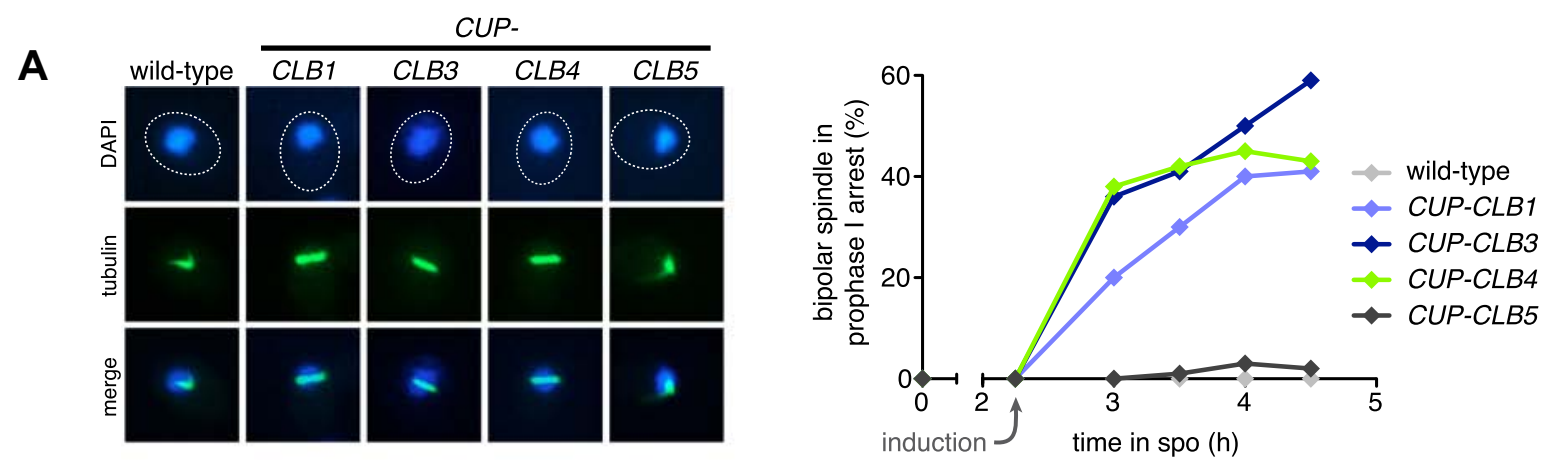

B

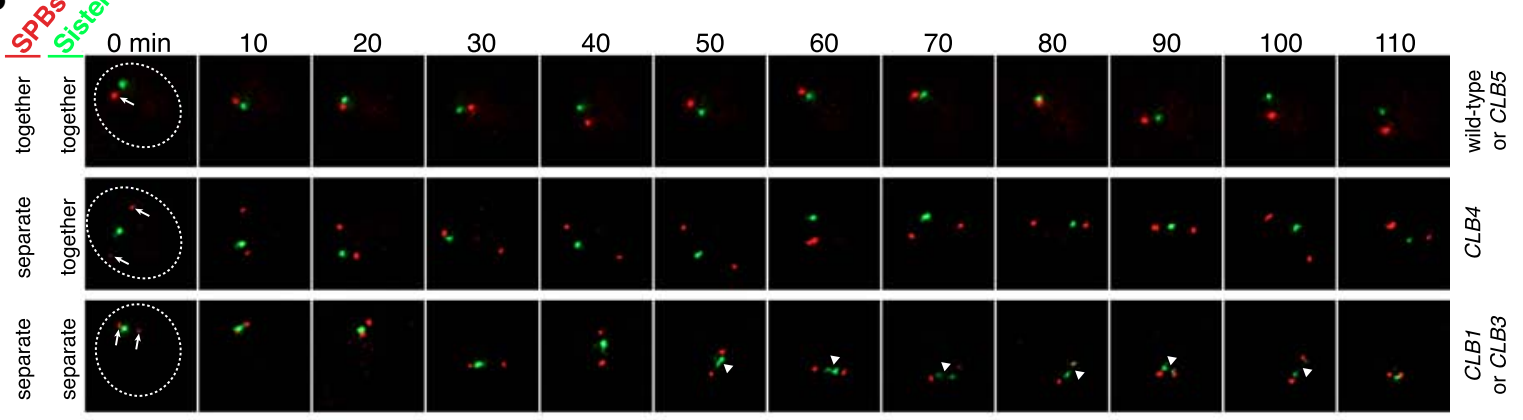

C
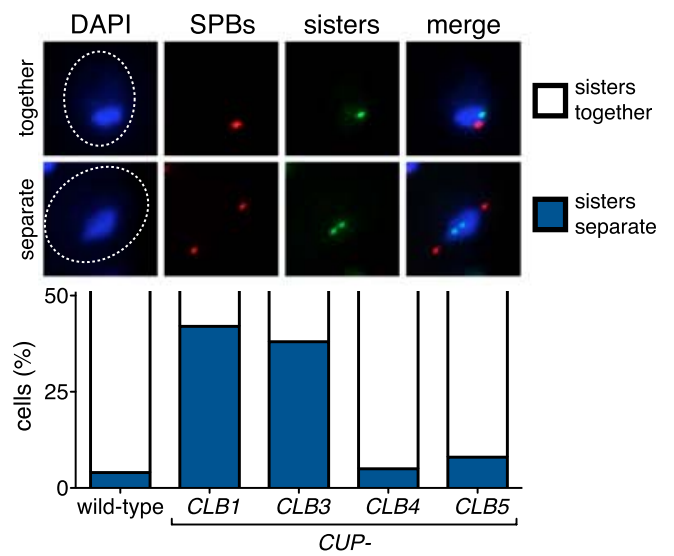

D
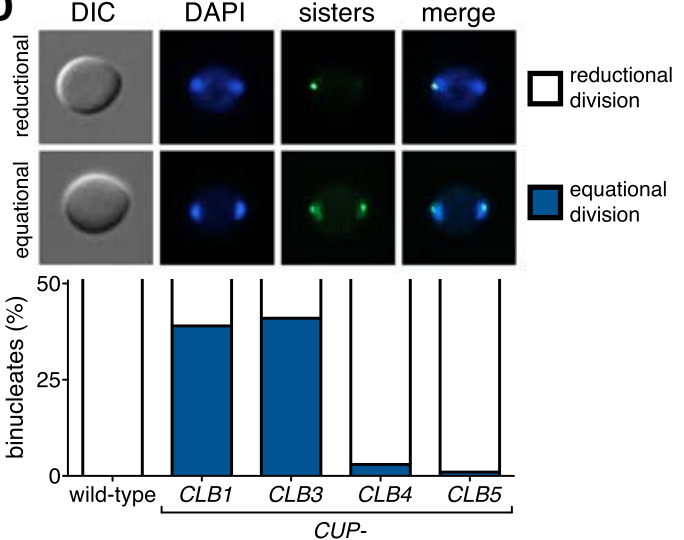

E
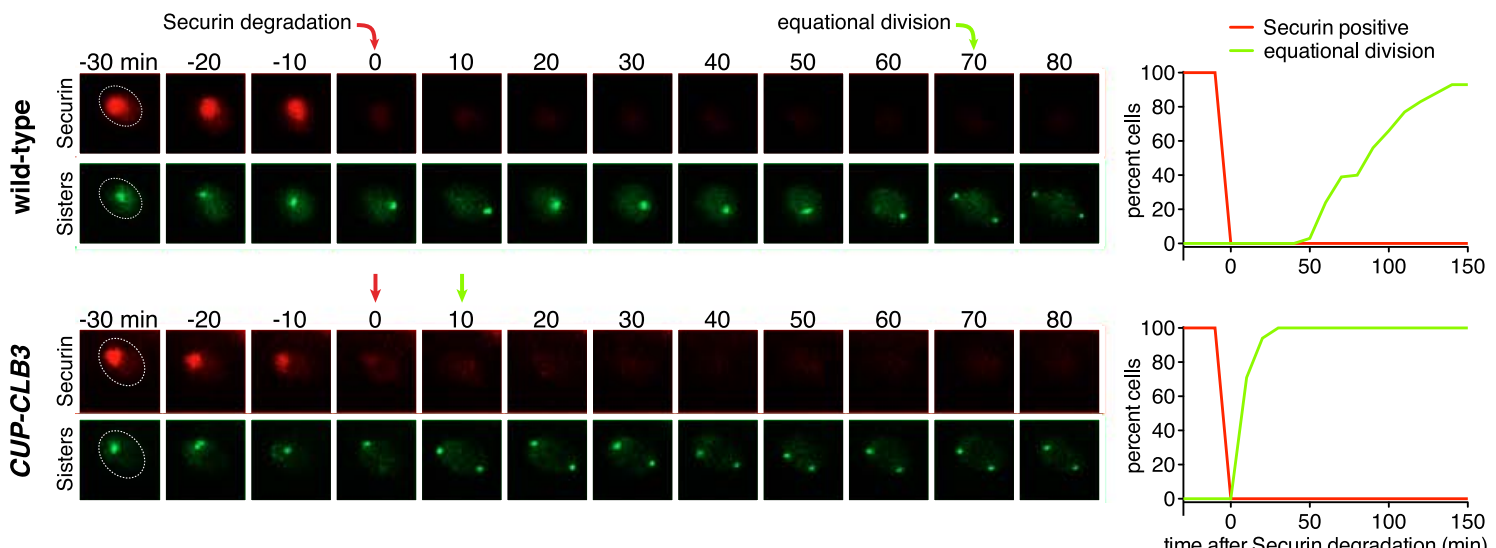

Figure 2. Premature expression of CLB1 or CLB3 causes sister kinetochore biorientation during prophase I and sister chromatid segregation in meiosis I. Wild-type or CUP-CLB cells were induced to sporulate. After $2 \mathrm{hr} 15 \mathrm{~min}$, cyclins were induced by addition of CuSO $\mathrm{S}_{4}(50 \mu \mathrm{M})$. Cells were either arrested during prophase I or released from an NDT80 block $4 \mathrm{hr} 30 \mathrm{~min}$ after induction of sporulation. (A) Bipolar spindle formation determined in wild-type (A22678), Figure 2. Continued on next page 
Figure 2. Continued

CUP-CLB1 (A27421), CUP-CLB3 (A22702), CUP-CLB4 (A27423) and CUP-CLB5 (A27425) during prophase I ( $n=100$ per time point). Images on left show spindle formation in CUP-CLB cells $4 \mathrm{hr}$ after induction of sporulation; in this and all subsequent Figures microtubules are shown in green and DNA in blue. The dotted line depicts the cell membrane. (B) Microtubule-kinetochore engagement monitored during prophase I, starting at $1 \mathrm{hr}$ after $\mathrm{CuSO}_{4}$ addition in wild-type (A30700), CUP-CLB1 (A30702), CUP-CLB3 (A30704), CUP-CLB4 (A30707) and CUP-CLB5 (A30708) by live cell microscopy. SPBs (marked by arrow) and heterozygous CENV-GFP dots are shown (arrowheads mark separated CENV dots). In this and all subsequent figures SPBs are in red, GFP dots are in green. (C) Top panel: representative images of wild-type (A30700) and CUP-CLB3 (A30704). Bottom panel: separation of heterozygous CENV-GFP dots in prophase l-arrested cells quantified in wild-type (A22678), CUP-CLB1 (A27421), CUP-CLB3 (A22702), CUP-CLB4 (A27423) and CUP-CLB5 (A27425) by live cell microscopy (over the duration of $8 \mathrm{hr}, \mathrm{n}>100$ ) as described in the 'Materials and methods'. The fraction of nuclei that display sister kinetochores as separate or together for each CUP-CLB strain was compared to wild-type using a chi-square test (df 1): CUP-CLB1, $X^{2}=40.77, p<0.0001 ;$ CUP-CLB3, $X^{2}=34.84, p<0.0001 ;$ CUP-CLB4, $X^{2}=0.1163, p=0.7330 ; C U P-C L B 5, X^{2}=1.418, p=0.2337$. (D) Segregation of sister chromatids (equational division) using heterozygous CENV-GFP dots quantified in binucleates from wild-type (A22678), CUP-CLB1 (A27421), CUP-CLB3 (A22702), CUP-CLB4 (A27423) and CUP-CLB5 (A27425) $(n=100)$. The fraction of binucleates that display a reductional or equational division for each CUP-CLB strain was compared to wild-type using a chi-square test (df 1): CUP-CLB1, $x^{2}=45.13, p<0.0001 ; C U P-C L B 3, X^{2}=48.22, p<0.0001 ; C U P-C L B 4$, $X^{2}=1.020, p=0.3124 ;$ CUP-CLB5, $X^{2}=0, p=1$. (E) Wild-type (A31019) and CUP-CLB3 (A31021) cells monitored for segregation of heterozygous CENV-GFP dots with respect to Pds1 (Securin, red) degradation by live cell microscopy ( $n>17$ ). Time of Pds1 degradation set to $t=0$, percent cells were plotted as a Kaplan-Meier curve. Note that for A31021, the analysis of cells that segregate sister chromatids in the first nuclear division is shown. Pds1 accumulation during prophase II is not observed using the Pds1-tdTomato construct, likely due to delayed maturation of the fluorophore (Katis et al., 2010).

DOI: 10.7554/eLife.00117.004

The following figure supplements are available for figure 2 .

Figure supplement 1 . Spindle pole body separation in CUP-CLB cells.

DOI: 10.7554/eLife.00117.005

Figure supplement 2. Homolog separation in CUP-CLB4 cells.

DOI: 10.7554/eLife.00117.006

Figure supplement 3. Chromosome III sister chromatid segregation in CUP-CLB3 cells.

DOI: 10.7554/eLife.00117.007

Figure supplement 4. Sister chromatid segregation in CUP-CLB3 cells using dual-color marked chromosomes. DOI: 10.7554/eLife.00117.008

Figure supplement 5. Recombination in CUP-CLB3 cells.

DOI: 10.7554/eLife.00117.009

Figure supplement 6. Localization of Rad51 in CUP-CLB3 cells.

DOI: 10.7554/eLife.00117.010

Figure supplement 7. Localization of Zip1 in CUP-CLB3 cells.

DOI: 10.7554/eLife.00117.011

Figure supplement 8. Preventing homologous recombination does not affect the phenotypes caused by premature CLB3 expression.

DOI: $10.7554 /$ eLife.00117.012

pachytene using the NDT80 block-release system. In this system, expression of NDT80 is controlled by the GAL1-10 promoter, which is regulated by an estrogen-inducible Gal4-ER fusion (Benjamin et al., 2003; Carlile and Amon, 2008). Cells were induced to sporulate and after $135 \mathrm{~min}$, copper was added to induce cyclin expression. $4 \mathrm{hr} 30 \mathrm{~min}$ after sporulation induction, estrogen was added to allow cells to synchronously proceed through the meiotic divisions. In wild-type, CUP-CLB4 and CUP-CLB5 cells, sister chromatids cosegregated in the first division, resulting in binucleate cells with a GFP dot in one of the two nuclei. In contrast, $39 \%$ of CUP-CLB1 and $41 \%$ of CUP-CLB3 cells segregated sister chromatids in the first division, as judged by the presence of binucleate cells with a GFP dot in each nucleus (Figure 2D). We observed a similar result for chromosome III and cells in which one copy of chromosome $\mathrm{V}$ was marked with a GFP dot and the other copy with an RFP dot (Figure 2figure supplements 3 and 4).

To confirm that sister chromatids indeed split during meiosis I in cells expressing CLB3 during prophase I, we examined when sister chromatid separation occurred with respect to Securin (Pds1 in budding yeast) degradation in CUP-CLB3 cells. In wild-type cells harboring heterozygous CENV-GFP dots, Pds1 degradation was immediately followed by movement of the single GFP dot to one side of the cell, indicating that homologous chromosomes had segregated. Subsequently, these cells underwent meiosis II and sister chromatids segregated (median = 86 min after Pds1 degradation; Figure 2E). In contrast, CUP-CLB3 cells segregated sister chromatids immediately after Pds1 degradation (median = 7 min after Pds1 degradation; Figure 2E). These results demonstrate that CUP-CLB3 cells 


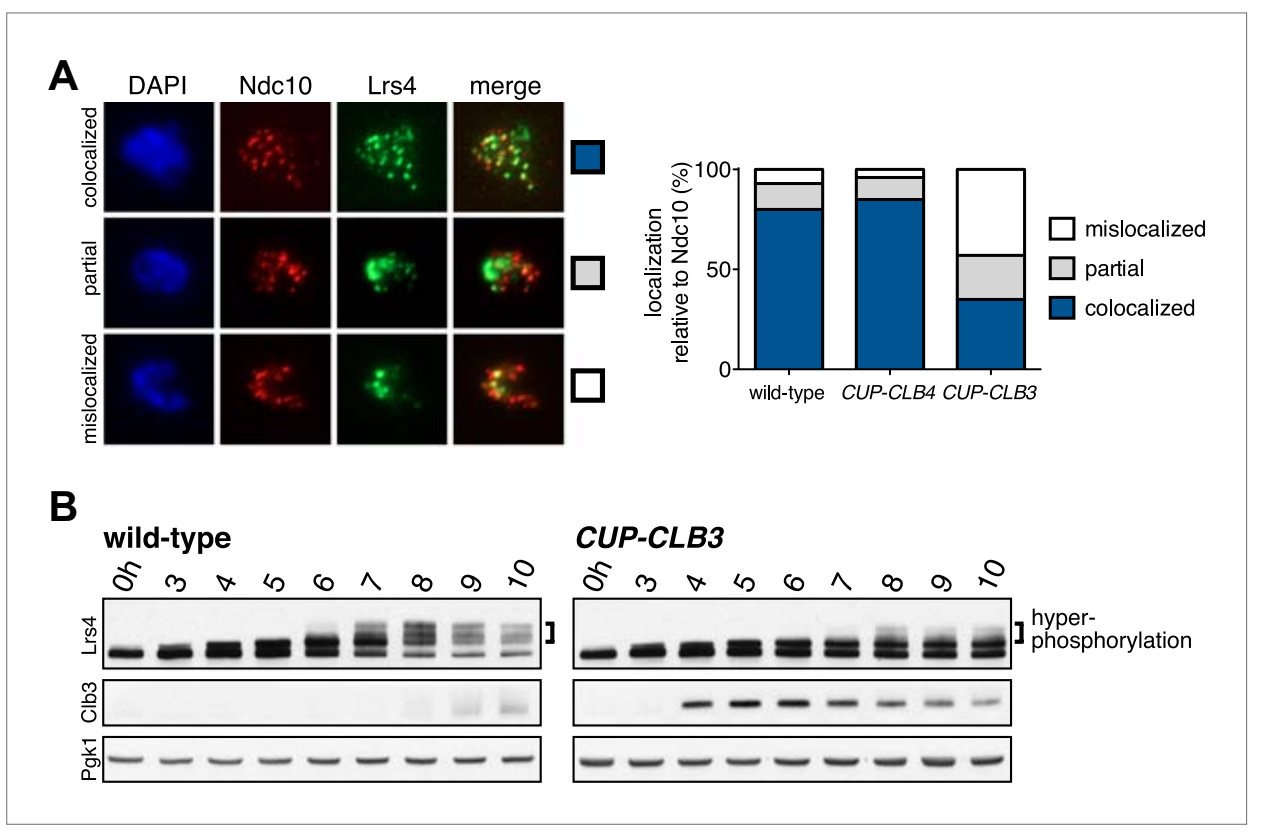

Figure 3. Premature CLB3 expression disrupts monopolin function. (A) Lrs4-13myc (green) localization relative to Ndc10-6HA (red) was determined in spread nuclei from wild-type (A9217), CUP-CLB3 (A26278) and CUP-CLB4 (A29643) harboring a Cdc20 depletion allele (cdc20-mn) were induced to undergo sporulation and arrested in metaphase I due to depletion of $\mathrm{Cdc} 20$. $\mathrm{CuSO}_{4}$ was added at $3 \mathrm{hr}$ after induction of sporulation $(\mathrm{n}>40)$. The fraction of spread nuclei that display colocalized, partial or mislocalized Lrs4 with respect to Ndc10 was compared to wild-type using a chi-square test (df 2): CUP-CLB4, $X^{2}=1.136, p=0.5666 ;$ CUP-CLB3, $X^{2}=45.84, p<0.0001$. (B) Western blots for Lrs4-13myc, Clb3 and Pgk1 from wild-type (A9217) and CUP-CLB3 (A26278) cells. Cells were sporulated as described in (A).

DOI: 10.7554/eLife.00117.013

The following figure supplements are available for figure 3 .

Figure supplement 1. Monopolin association with kinetochores is disrupted in CUP-CLB3 but not in CUP-CLB4 cells. DOI: 10.7554/eLife.00117.014

Figure supplement 2. Premature Clb3 expression does not interfere with Mam1 expression. DOI: 10.7554/eLife.00117.015

Figure supplement 3. Lrs4 phosphorylation is not disrupted in CUP-CLB4 cells. DOI: 10.7554/eLife.00117.016

segregate sister chromatids during the first meiotic division. Thus, CUP-CLB3 cells must be defective in two key aspects of meiosis I chromosome segregation: coorientation of sister kinetochores and maintenance of centromeric cohesion. We note that another essential aspect of meiosis I chromosome segregation, homologous recombination, was not affected by premature CLB3 expression. We observed no major defects in DSB formation, synaptonemal complex assembly and generation of recombination products, nor did preventing homologous recombination affect the phenotypes caused by premature CLB3 expression (Figure 2-figure supplements 5-8).

\section{Premature expression of CLB3 interferes with monopolin localization}

The finding that CUP-CLB1 or CUP-CLB3 cells segregate sister chromatids during meiosis I indicates that sister kinetochore coorientation is defective. To investigate this further, we examined monopolin localization in cells that segregate sister chromatids in meiosis I (CUP-CLB3 cells) and cells that do not exhibit chromosome missegregation despite cyclin misexpression (CUP-CLB4 cells). Colocalization of Lrs4 or Mam1 with the kinetochore component Ndc10 was dramatically reduced in CUP-CLB3 but not CUP-CLB4 cells (Figure 3A and Figure 3-figure supplements 1 and 2). Hyperphosphorylation of Lrs4, which correlates with monopolin function (Clyne et al., 2003; Lee and Amon, 2003; Matos et al., 2008), was also significantly reduced in CUP-CLB3, but not in CUP-CLB4 cells (Figure $3 B$ and Figure 3-figure supplement 3). These results indicate that premature expression of CLB3 prevents monopolin association with kinetochores. 


\section{Centromeric cohesin is lost during meiosis I in CUP-CLB3 cells}

Sister chromatids segregate during meiosis I in CUP-CLB3 cells, indicating that centromeric cohesin either fails to associate with chromosomes or is lost prematurely. To test the first possibility, we examined chromosome association of the cohesin subunit Rec8 and the cohesion maintenance factor Pds5 with chromosomes. Chromatin immunoprecipitation (ChIP) and chromosome spreads revealed that association of both proteins with chromosomes in CUP-CLB3 cells was indistinguishable from that of wild-type cells during prophase I or metaphase I (Figure 4A and Figure 4figure supplements 1 and 2). Thus, loading of cohesion factors onto chromosomes is not affected in CUP-CLB3 cells.

To test the possibility that CUP-CLB3 cells fail to maintain centromeric cohesion beyond anaphase I, we first determined the localization of the cohesin subunit Rec8 in cells that had progressed past metaphase I. Rec8 colocalized with the kinetochore component Ndc10 in binucleate wild-type and CUP-CLB4 cells, demonstrating that centromeric cohesin is protected from removal until the onset of anaphase II. In contrast, Rec8 was not detected around centromeres in a substantial fraction of binucleate CUP-CLB3 cells (Figure 4B). Functional assays confirmed the defect in centromeric cohesion maintenance in CUP-CLB3 cells. Although mam1 14 cells biorient sister chromatids during meiosis I, they delay nuclear division until meiosis II due to the presence of centromeric cohesin (Toth et alo, 2000; Rabitsch et al., 2003). The delay in nuclear division of a mam $1 \Delta$ was partially alleviated by the expression of CUP-CLB3 (Figure 4-figure supplement 3). This partial effect is likely due to not all CUP-CLB3 cells losing centromeric cohesion prematurely in meiosis I (Figure 4B). We conclude that both centromeric and arm cohesin are lost from chromosomes at the onset of anaphase I in CUP-CLB3 cells.

Next, we investigated the cause of premature centromeric cohesin removal in CUP-CLB3 cells. Cleavage of cohesin by separase requires the phosphorylation of Rec8 at multiple residues (Brar et al., 2006; Katis et al., 2010). A recessive allele of REC8 in which 29 in vivo phosphorylation sites were mutated to alanine (rec8-29A) (Brar et al., 2006) was not cleaved in CUP-CLB3 cells, but wild-type Rec8 was (Figure $4 C$ and Figure 4-figure supplement 4). Furthermore, the rec8-29A allele caused a similar metaphase I delay in wild-type and CUP-CLB3 cells when expressed as the sole source of REC8 (Figure 4D and Figure 4-figure supplements 5 and 6). We noticed that the Rec8 cleavage product was detected at lower levels in CUP-CLB3 cells (Figure 4C and Figure 4-figure supplement 5). The cause of this reduction is currently unclear, but could indicate that in CUP-CLB3 cells, cohesin removal also relies on a separase-independent pathway, that is the prophase removal pathway (Yu and Koshland, 2005).

Our results demonstrate that Rec8 phosphorylation is required for cohesin removal in CUP-CLB3 cells and suggest that the defect in centromeric cohesin protection may result from increased phosphorylation of centromeric Rec8. To test this possibility, we used phospho-specific antibodies against two in vivo phosphorylation sites of Rec8 (pS179 and pS521) (Brar et al., 2006; Katis et al., 2010; M. Attner personal communication, October 2011) and analyzed the relative enrichment of total Rec8 and phospho-Rec8 at CENV or at an arm cohesin binding site by ChIP in metaphase l-arrested cells. The two phospho-specific antibodies immunoprecipitated similar amounts of Rec8 in wild-type and CUP-CLB3 cells at the arm site (Figure 4E), which is consistent with arm cohesin being primed for Separase cleavage. However, the amount of phosphorylated Rec8 was increased at the centromere in CUP-CLB3 cells compared to wild-type cells, albeit not to the same extent as in cells depleted for Sgo1 (sgo1-mn), in which meiosis I centromeric-cohesin protection is completely defective (Figure 4E). We conclude that CUP-CLB3 cells are compromised in preventing centromeric Rec8 phosphorylation during meiosis $\mathrm{I}$.

\section{Sgo1-PP2A localization is not affected in CUP-CLB3 cells}

Sgo1-PP2A and the meiosis-specific protein Spo13 prevent centromeric Rec8 phosphorylation during meiosis I to protect this cohesin pool from cleavage. All three proteins localize to kinetochores during meiosis I, which is thought to be critical for their cohesin-protective function (Katis et al., 2004a, 2004b; Kitajima et al., 2004; Lee et al., 2004; Kitajima et al., 2006; Riedel et al., 2006). Surprisingly, Sgo1, the PP2A regulatory subunit Rts1 and Spo13 localized normally in prophase I- and metaphase I-arrested CUP-CLB3 cells (Figure 4F-H and Figure 4-figure supplements 7-9). We noticed a moderate reduction of Sgo1 and Rts1 at centromeres in binucleate CUP-CLB3 cells (Figure 4I and Figure 4-figure supplement 10). However, this reduction during anaphase I is most likely a consequence 
A
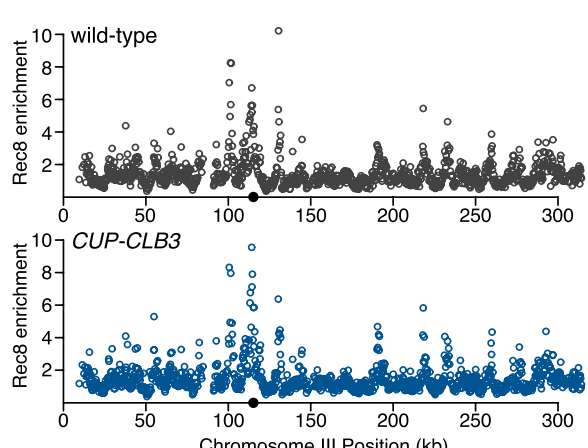
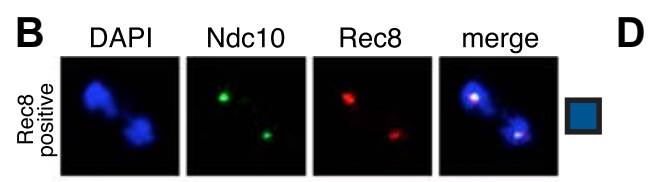

D
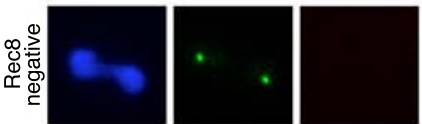

$\square$ Rec8 negative

$\square$ Rec8 positive

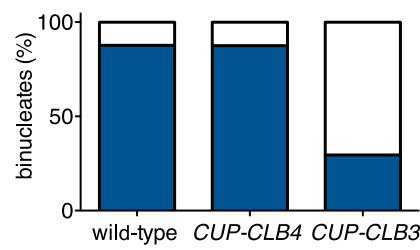

wild-type

CUP-CLB

$\rightarrow$ rec8-29A

$\rightarrow$ CUP-CLB3 rec8-29A

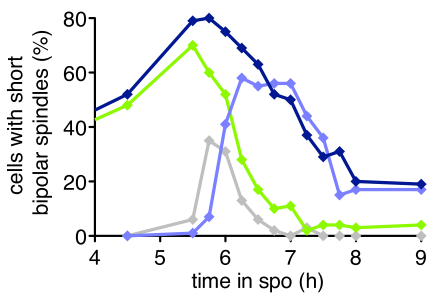

C REC8-myc/REC8-HA

REC8-myc/rec8-29A-HA

REC8-myc/REC8-HA CUP-CLB3

REC8-myc/rec8-29A-HA CUP-CLB3

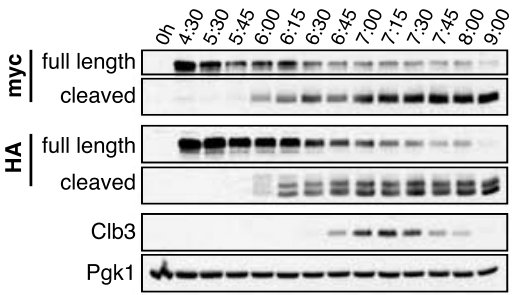

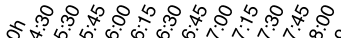
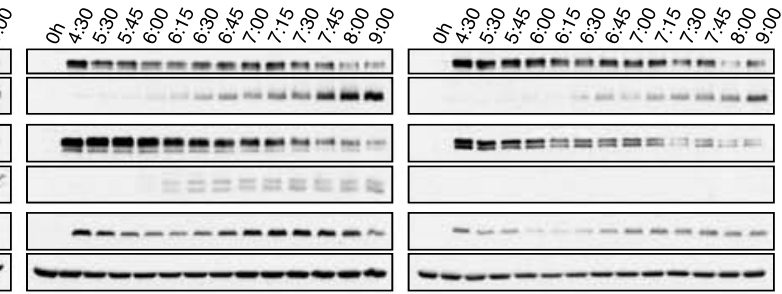

E

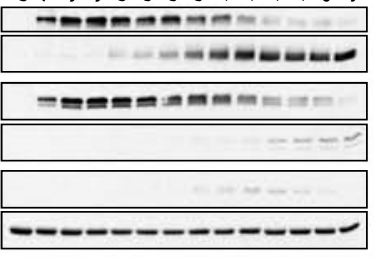

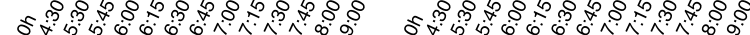

Rec8

Rec8 p-S179
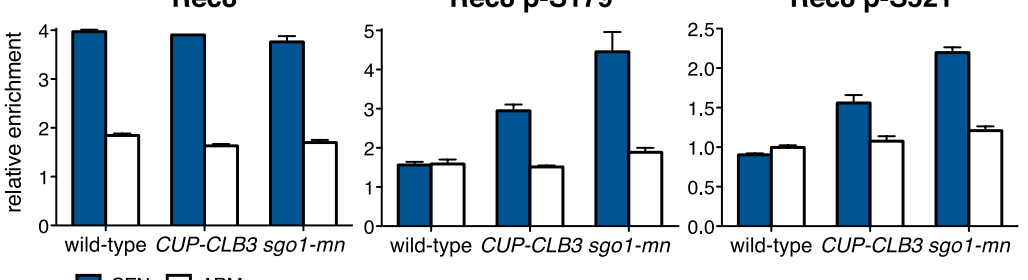

$\mathbf{F}$ $\square$ CEN $\square$ ARM

G

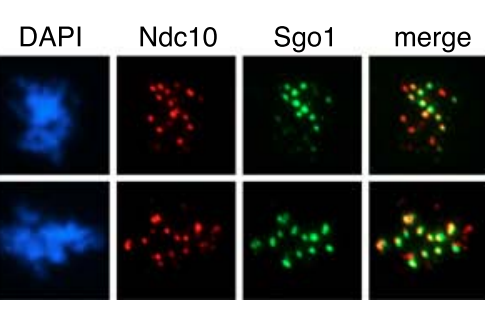

H
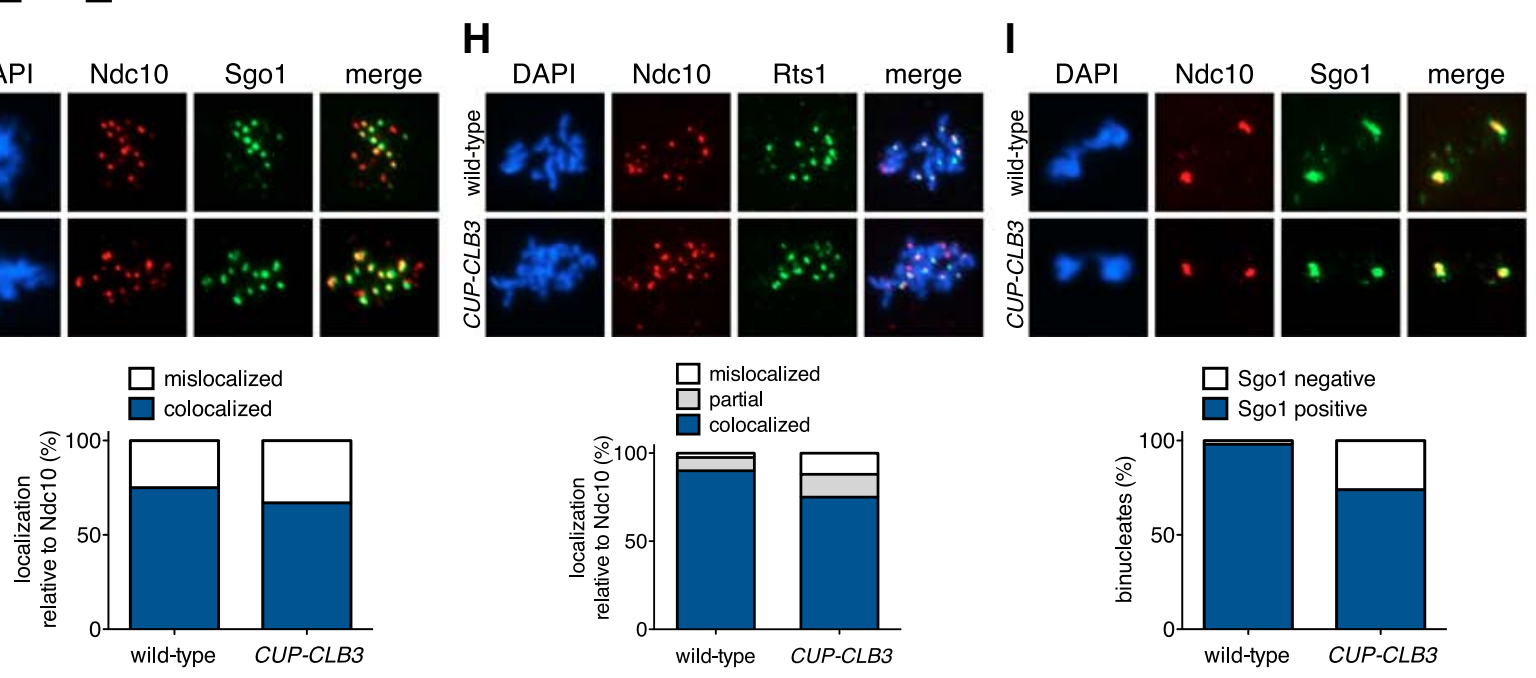

Figure 4. CLB3 misexpression disrupts protection of centromeric cohesin. Cyclin expression was induced after $2 \mathrm{hr} 15 \mathrm{~min}$ (C) and (D), $2 \mathrm{hr} 30 \mathrm{~min}$ (A), (B), (E), (F) and (H) or $3 \mathrm{hr}(\mathbf{G})$ and (I) of sporulation. (A) Chromosomal association of Rec8-13myc was monitored by ChIP-chip in wild-type (A28716) and CUP-CLB3 (A28718) during prophase I arrest. Centromere position is identified by a black circle. (B) Centromeric Rec8 localization was monitored in Figure 4. Continued on next page 
Figure 4. Continued

spread nuclei from wild-type (A28684), CUP-CLB3 (A28685) and CUP-CLB4 (A28686) cells carrying REC8-3HA (red) and NDC10-13myc (green) ( $>$ > 40). The fraction of spread nuclei that were Rec8 positive or negative was compared to wild-type using a chi-square test (df 1$)$ : CUP-CLB4, $X^{2}=0.001323$, $\mathrm{p}=0.9710$; CUP-CLB3, $\mathrm{x}^{2}=32.79, \mathrm{p}<0.0001$. (C) Rec8 cleavage monitored by Western blot after release from an NDT80 block (4 hr $30 \mathrm{~min}$ ) in wild-type and CUP-CLB3 carrying both a myc-tagged REC8 allele as well as either HA-tagged REC8 or rec8-29A allele (left to right: A29957, A29959, A29961, A29963). (D) Percentage of cells with short bipolar spindles was determined at indicated times in wild-type (A22804), CUP-CLB3 (A29965), rec8-29A (A22803) and CUP-CLB3 rec8-29A (A29967) after release from an NDT80 block (4 hr $30 \mathrm{~min}$ ) ( $\mathrm{n}=100$ per time point). (E) ChIP analysis for total Rec8, p-S179 Rec8 or p-S521 Rec8 from metaphase l-arrested (cdc20-mn) wild-type (A28681), CUP-CLB3 (A28682) and Sgo1-depleted (sgo1-mn; A29994) cells. Relative occupancy at a chromosome arm site (c194) or at a centromeric site (CENV) was determined relative to a low binding region (c281). Error bars represent range $(n=2)$. (F) Chromosomal association of Sgo1-3V5 was monitored by ChIP-chip in wild-type (A29795) and CUP-CLB3 (A29799) cells during prophase l-arrest. Centromere position is identified by a black circle. (G), (H) Localization of Sgo1-9myc (G, green) or Rts1-13myc (H, green) relative to Ndc10-6HA (red) determined by nuclear spreads in (G) wild-type (A22868) and CUP-CLB3 (A22870) or (H) wild-type (A28329) and CUP-CLB3 (A28330) during prophase I ( $\mathrm{>}>40)$. For (G), the fraction of spread nuclei that display colocalized or mislocalized Sgo1 relative to Ndc10 was compared between wild-type and CUP-CLB3 using a chi-square test ( $\mathrm{df} 1) \mathrm{X}^{2}=1.554, \mathrm{p}=0.2125$. For $(\mathbf{H})$, the fraction of spread nuclei that display colocalized, partial or mislocalized Rts1 relative to Ndc10 was compared between wild-type and CUP-CLB3 using a chi-square test (df 2) $X^{2}=3.712, p=0.1563$. (I) Localization of Sgo1-9myc (green) in binucleates relative to Ndc10-6HA (red) determined by nuclear spreads from wild-type (A22868) and CUP-CLB3 (A22870)

$(n>40)$. The fraction of spread nuclei that were Sgo1 positive or negative was compared between wild-type and CUP-CLB3 using a chi-square test (df 1 ) $X^{2}=23.92, p<0.0001$

DOI: $10.7554 /$ eLife.00117.017

The following figure supplements are available for figure 4.

Figure supplement 1. Chromosomal association of Rec8 in CUP-CLB3 cells.

DOI: 10.7554/eLife.00117.018

Figure supplement 2. Chromosomal association of Pds5 in CUP-CLB3 cells.

DOI: 10.7554/eLife.00117.019

Figure supplement 3. CUP-CLB3 cells partially bypass the nuclear division delay of mam1 $\Delta$ cells. DOI: 10.7554/eLife.00117.020

Figure supplement 4. Meiotic progression of the cells analyzed for Rec8 cleavage in Figure $\mathbf{4 C}$. DOI: 10.7554/eLife.00117.021

Figure supplement 5. Analysis of Rec8 cleavage in cells used for Figure 4D.

DOI: 10.7554/eLife.00117.022

Figure supplement 6. Meiotic progression of the cells analyzed for Rec8 cleavage in Figure 4D.

DOI: 10.7554/eLife.00117.023

Figure supplement 7. Chromosomal association of Sgo1 in CUP-CLB3 cells.

DOI: 10.7554/eLife.00117.024

Figure supplement 8. Localization of Rts1 in CUP-CLB3 cells.

DOI: 10.7554/eLife.00117.025

Figure supplement 9. Chromosomal association of Spo13 in CUP-CLB3 cells.

DOI: 10.7554/eLife.00117.026

Figure supplement 10. Rts1 localization in binucleate CUP-CLB3 cells.

DOI: 10.7554/eLife.00117.027

Figure supplement 11. Analysis of Rts1 localization in Rec8 phosphomimetic mutants.

DOI: 10.7554/eLife.00117.028

rather than a cause of premature loss of centromeric cohesin. In cells expressing a phosphomimetic version of Rec8 (rec8-4D) that cannot be retained at centromeres beyond meiosis I, Rts 1 localization is also reduced in anaphase I (Figure 4-figure supplement 11). It is thus unlikely that the reduction of Sgo1 and Rts1 at centromeres during anaphase I contributes to the premature loss of centromeric cohesin. These findings, together with our observation that centromeric Rec8 phosphorylation is increased in CUP-CLB3 cells, indicate that Sgo1-PP2A function, but not localization, is impaired in CUP-CLB3 cells.

\section{Modulating microtubule-kinetochore interactions affects monopolin-induced sister chromatid cosegregation during mitosis}

How does premature expression of CLB3 interfere with establishment of the meiosis I chromosome segregation pattern? The comparison of the effects caused by CLB3 and CLB4 misexpression provided insight into this question. Both cyclins induce spindle formation in prophase I. However, chromosomes are able to attach to this spindle and experience pulling forces only in CUP-CLB3 cells. Thus, 
the ability to form tension-generating attachments (i.e. CUP-CLB1 or CUP-CLB3 cells) correlates with defects in meiosis I chromosome morphogenesis and segregation. This correlation suggests that premature microtubule-kinetochore engagement during premeiotic $S$ phase/early prophase $I$ is the underlying cause of chromosome missegregation in CUP-CLB3 cells and predicts that tension generating microtubule-kinetochore attachments should inhibit meiosis I chromosome morphogenesis. Conversely, preventing them should enable building a proper meiosis I chromosome architecture.

We tested the first prediction using a previously described method in which monopolin-dependent sister kinetochore coorientation is induced during mitosis (Monje-Casas et al., 2007). Overexpression of MAM1 and CDC5 upon a pheromone-induced G1 arrest is sufficient to induce cosegregation of sister chromatids in mitotic anaphase (Monje-Casas et alo, 2007, Figure 5A). However, when cells are allowed to form microtubule-kinetochore attachments prior to CDC5 and MAM1 expression, cosegregation of sister chromatids is prevented. We reversibly arrested cells in metaphase using a methionine repressible CDC20 allele (MET-CDC20) and induced MAM1 and CDC5 expression after cells had arrested in metaphase and had formed microtubule-kinetochore interactions. Under these conditions, MAM1 and CDC5 expression did not induce sister chromatid cosegregation when cells were released into anaphase (Figure $5 \mathrm{~A}$ ). Importantly, disrupting microtubule-kinetochore interactions by depolymerizing microtubules with nocodazole during the metaphase arrest resulted in robust cosegregation of sister chromatids in anaphase (48\% cosegregation, Figure $5 \mathrm{~A})$. These results show that microtubule-kinetochore interactions modulate the ability of monopolin to induce sister chromatid cosegregation.

\section{Transient disruption of microtubule-kinetochore interactions restores meiosis I chromosome segregation in CUP-CLB3 cells}

If the defects in sister kinetochore coorientation and centromeric cohesin maintenance of CUP-CLB3 cells are caused by premature microtubule-kinetochore interactions, proper meiosis I chromosome morphogenesis should be restored by transiently disrupting microtubule-kinetochore interactions. To test this, we used a temperature sensitive allele of NDC80 (ndc80-1), which encodes a component of the outer kinetochore. ndc80-1 cells grow and sporulate normally at $25^{\circ} \mathrm{C}$, but fail to undergo any nuclear divisions at temperatures above $34^{\circ} \mathrm{C}$ (Figure 5-figure supplement 1).

We first asked whether disrupting microtubule-kinetochore interactions suppresses the kinetochore localization defect of monopolin in CUP-CLB3 cells. Using the NDT80 block-release system, we induced cells to sporulate at $25^{\circ} \mathrm{C}$. After $165 \mathrm{~min}$, we induced cyclin expression and concurrently transferred cells to $34^{\circ} \mathrm{C}$ to inactivate the ndc80-1 allele. Cells were then incubated for an additional $135 \mathrm{~min}$ to arrest them in the NDT80-depletion block. We then transferred cells to the permissive temperature and released them from the NDT80 block into a metaphase l-arrest by depleting CDC20 (cdc20-mn) (Figure 5B). Under these conditions, wild-type and ndc80-1 cells arrested in metaphase I with the monopolin subunit Lrs4 localized to kinetochores, while CUP-CLB3 cells showed a defect in Lrs4 localization (Figure 5C). Remarkably, CUP-CLB3 ndc80-1 cells showed near wild-type levels of Lrs4 association with kinetochores (Figure $5 \mathrm{C}$ ). Transient inactivation of $\mathrm{Ndc} 80$ also restored Lrs4 phosphorylation in CUP-CLB3 cells (Figure 5D). Our results demonstrate that premature microtubule-kinetochore interactions prevent sister kinetochore coorientation by disrupting proper localization of the monopolin complex. The finding that transient disruption of microtubule-kinetochore interactions also suppresses the Lrs4 phosphorylation defect of CUP-CLB3 cells, furthermore suggests that Lrs4 hyperphosphorylation occurs not at the time of nucleolar release, but once Lrs4 localizes to kinetochores.

We next asked whether transient inactivation of microtubule-kinetochore interactions also suppresses the premature loss of centromeric cohesin observed in CUP-CLB3 cells. We used a similar protocol to the one described above, except cells were not arrested in metaphase I following release from the NDT80 block, but were allowed to proceed into anaphase I to examine Rec8 localization. Remarkably, disrupting microtubule-kinetochore interactions at the time of $\mathrm{Clb} 3$ expression caused a considerable increase in the percentage of CUP-CLB3 cells that retained Rec8 around centromeres during anaphase I (Figure 5E).

Finally, restoring centromeric cohesin protection and sister kinetochore coorientation to CUP-CLB3 cells by transient inactivation of $\mathrm{Ndc} 80$ restored homolog segregation during meiosis I (Figure $\mathbf{5 F}$ and Figure 5-figure supplements 2-4). Similar results were obtained with a temperature sensitive allele of the gene encoding the outer kinetochore component Dam1 (dam1-1) or by disrupting microtubule-kinetochore interactions by benomyl treatment (Figure 5-figure supplements 5 and 6). We 
A
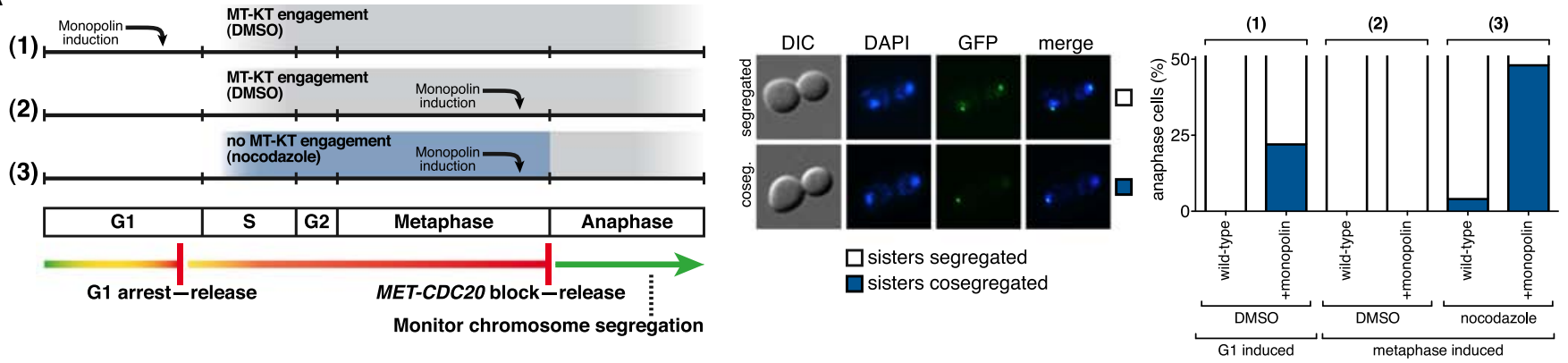

B

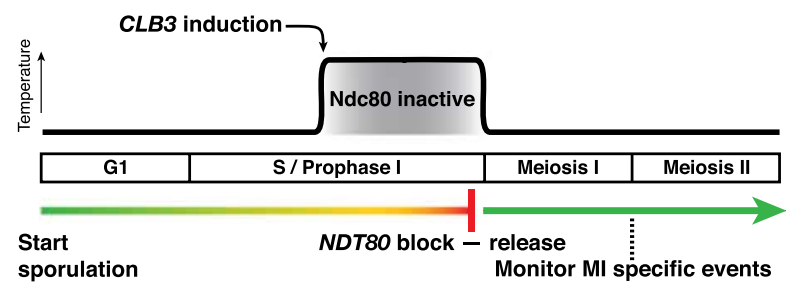

C

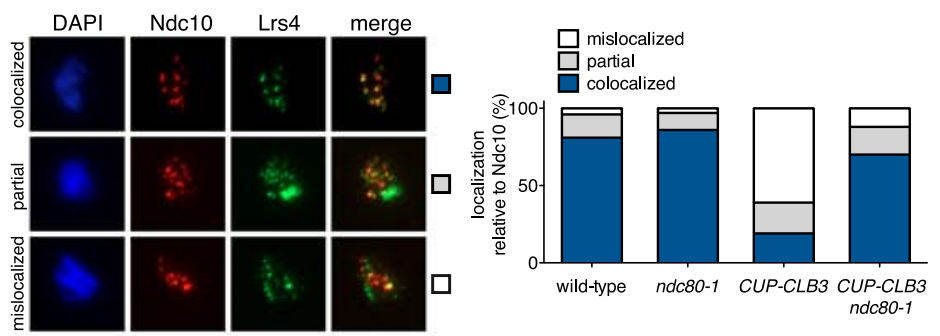

D wild-type

ndc80-1

CUP-CLB3

CUP-CLB3 ndc80-1
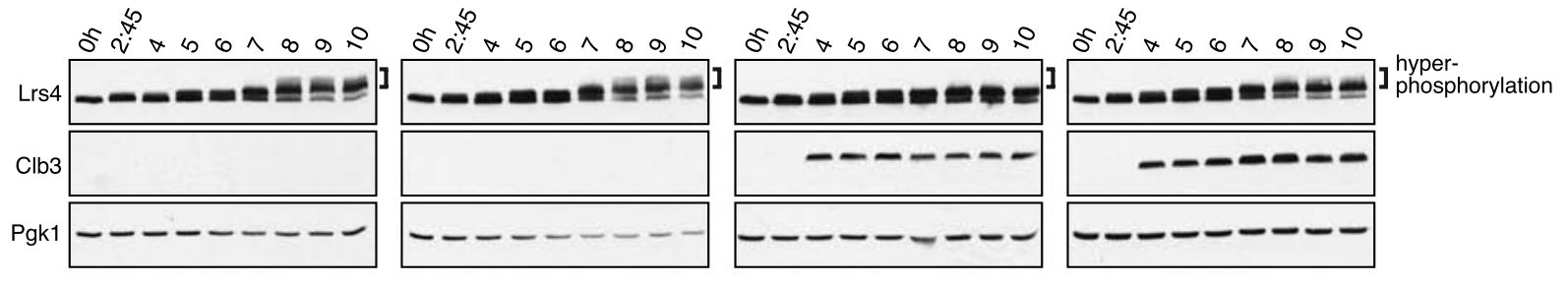

E

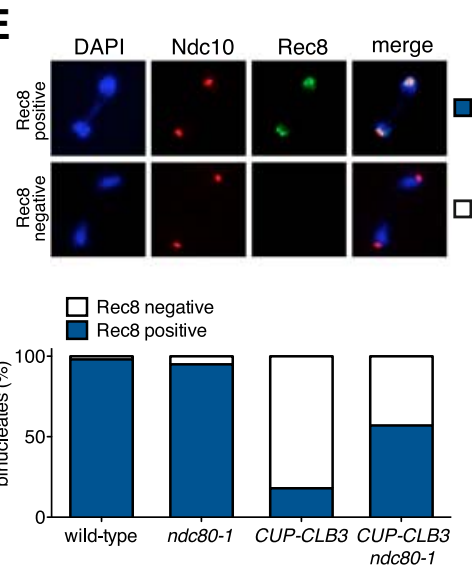

$\mathbf{F}$

G

H
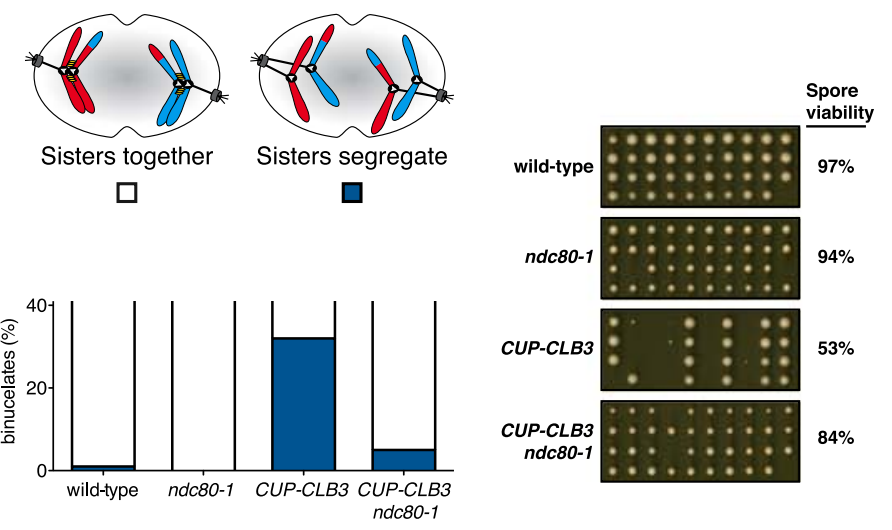

\begin{tabular}{|c|c|c|c|c|}
\hline wild-type & 99 & 1 & 0 & 0 \\
\hline$n d c 80-1$ & 98 & 2 & 0 & \\
\hline CUP-CLB3 & 84 & 8 & 8 & \\
\hline $\begin{array}{l}\text { CUP-CLBB3 } \\
\text { ndCBO-1 }\end{array}$ & 92 & 6 & 2 & \\
\hline $37^{\circ} \mathrm{C}$ & \multicolumn{4}{|c|}{ 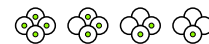 } \\
\hline wild-type & 90 & 4 & 6 & 0 \\
\hline$n d c 80-1$ & 95 & 3 & 2 & \\
\hline CUP-CLB3 & 30 & 44 & 26 & \\
\hline CUP-CLB3 & 79 & 9 & 12 & \\
\hline
\end{tabular}

Figure 5. Transient disruption of microtubule-kinetochore interactions suppresses the chromosome segregation defects in CUP-CLB3 cells. (A) Wild-type (A10684) and GAL-CDC5 GAL-MAM1 (A26546) cells, carrying a MET-CDC20 allele and CENIV-GFP dots, were monitored for chromosome segregation in anaphase (see 'Materials and methods' for details). MT = microtubule, KT = kinetochore, $(n=100)$. The fraction of anaphase cells that segregate or cosegregate sister chromatids was compared between GAL-CDC5 GAL-MAM1 condition (2) and GAL-CDC5 GAL-MAM1 condition (3) using a chi-square test ( $d f$ 1) $X^{2}=59.71, p<0.0001$. (B) Schematic description of the experimental regime used for (C) through (H) see 'Materials and methods' for details. (C) Localization of Lrs4-13myc (green) in mononucleates relative to Ndc10-6HA (red) determined by nuclear Figure 5. Continued on next page 
Figure 5. Continued

spreads ( $n>40$ ) and (D) phosphorylation of Lrs4-13myc determined by gel mobility shift in wild-type (A29612), ndc80-1 (A29614), CUP-CLB3 (A29616) and CUP-CLB3 ndc80-1 (A29618). For (C), using a chi-square test (df 2) the fraction of spread nuclei that display colocalized, partial or mislocalized Lrs4 with respect to Ndc10 was compared between wild-type and $n d c 80-1 X^{2}=0.9668, p=0.6167$ and between CUP-CLB3 and CUP-CLB3 ndc80-1 $X^{2}=56.34, p<0.0001$. (E) Localization of Rec8-13myc (green) in binucleates relative to Ndc10-6HA (red) determined by nuclear spreads in wild-type (A28716), ndc80-1 (A28720), CUP-CLB3 (A28718) and CUP-CLB3 ndc80-1 (A28722) ( $>$ 40). Using a chi-square test (df 1) the fraction of spread nuclei that were Rec8 positive or negative was compared between wild-type and ndc80-1 $X^{2}=1.185, p=0.2764$ and between CUP-CLB3 and CUP-CLB3 ndc80-1 $x^{2}=23.96, p<0.0001$. (F) Segregation of sister chromatids using heterozygous CENV-GFP dots quantified in binucleates $(n=100)$ and (G) spore viability from wild-type (A22678), ndc80-1 (A28621), CUP-CLB3 (A22702) and CUP-CLB3 ndc80-1 (A28623) ( $n=40$ tetrads for wild-type and ndc80-1, n> 60 tetrads for CUP-CLB3 and CUP-CLB3 ndc80-1) (nonpermissive temperature $>36^{\circ} \mathrm{C}$ ). Using a chi-square test (df 1) the fraction of binucleates with a reductional or equational division was compared between CUP-CLB3 and CUP-CLB3 ndc80-1 $X^{2}=24.18, p<0.0001$. (G) Segregation of chromosome V using homozygous CENV-GFP dots quantified in tetranucleates from wild-type (A22688), ndc80-1 (A28625), CUP-CLB3 (A22708) and CUP-CLB3 ndc80-1 (A28627). Top panel: cells kept at $25^{\circ} \mathrm{C}$ for the duration of the experiment. Bottom panel: Cells treated as in (B) but monitored after meiosis II $(n=100)$.

DOI: 10.7554/eLife.00117.029

The following figure supplements are available for figure 5 .

Figure supplement 1. Sporulation efficiency of ndc80-1 mutants.

DOI: 10.7554/eLife.00117.030

Figure supplement 2. Sister kinetochore coorientation in ndc80-1 cells under a continuous inactivation regime at $34^{\circ} \mathrm{C}$ during a metaphase I arrest. DOI: 10.7554/eLife.00117.031

Figure supplement 3. Sister kinetochore coorientation in ndc80-1 cells after transient inactivation regime at $34^{\circ} \mathrm{C}$ during a metaphase I arrest. DOI: 10.7554/eLife.00117.032

Figure supplement 4. Meiosis I chromosome segregation in ndc80-1 cells after a transient inactivation regime at $34^{\circ} \mathrm{C}$ DOI: 10.7554/eLife.00117.033

Figure supplement 5. Transient disruption of microtubule-kinetochore interactions using dam1-1 allele restores meiosis I chromosome segregation in CUP-CLB3 cells.

DOI: 10.7554/eLife.00117.034

Figure supplement 6. Transient disruption of microtubule-kinetochore interactions by benomyl treatment restores meiosis I chromosome segregation in CUP-CLB3 cells.

DOI: 10.7554/eLife.00117.035

Figure supplement 7. Transient disruption of microtubule-kinetochore interactions during S phase/prophase I suppresses CUP-CLB3-induced meiosis I sister chromatid segregation in a spindle assembly checkpoint independent manner.

DOI: 10.7554/eLife.00117.036

Figure supplement 8. Transient disruption of microtubule-kinetochore interactions during S phase/prophase I restores meiotic chromosome segregation in CUP-CLB3 cells in a spindle assembly checkpoint independent manner.

DOI: 10.7554/eLife.00117.037

Figure supplement 9. Transient ndc80-1 inactivation does not alter in vitro Cdk1 activity

DOI: 10.7554/eLife.00117.038

further observed a striking improvement in overall chromosome segregation and spore viability in CUP-CLB3 ndc80-1 compared to CUP-CLB3 cells (Figure 5G,H). The suppression of chromosome missegregation in CUP-CLB3 ndc80-1 cells did not depend on the spindle assembly checkpoint, because deletion of MAD3 had no discernable effect on the extent of ndc80-1 mediated suppression (Figure 5-figure supplements 7 and 8), nor was it due to the ndc80-1 allele lowering Clb3-CDK activity (Figure 5-figure supplement 9). In summary, our results demonstrate that the defects associated with CUP-CLB3 cells are due to premature microtubule-kinetochore interactions. Our results further suggest that preventing microtubule-kinetochore interactions during premeiotic $S$ phase and prophase I is necessary to establish a meiosis I-specific chromosome architecture.

\section{The outer kinetochore is disassembled during premeiotic S phase and prophase I}

Our results demonstrate that preventing premature interactions of microtubules with kinetochores is essential for establishing a meiosis I chromosome architecture. This occurs, at least in part, by restricting Clb-CDK activity during premeiotic S phase and prophase I. Are additional mechanisms in place to prevent premature microtubule-kinetochore interactions? Insight into this question came from the variability in CUP-CLB3-associated phenotypes. 
We initially noticed that the timing of CLB3 induction had an impact on the extent of sister chromatid segregation in meiosis I, especially in experiments that employed the NDT80 block-release system. To investigate this further, we expressed CLB3 at different times after induction of sporulation. We observed that the extent of meiosis I sister chromatid segregation declined as CLB3 was expressed later during the NDT80 block (Figure 6A). One possibility is that CLB3-induced sister chromatid segregation depends on additional factors that become limiting. Kinetochore components are good candidates for such additional factors, because previous studies in fission yeast demonstrated that a subset of outer kinetochore components dissociates from the kinetochore during prophase I (Asakawa et al., 2005).

Using a high-resolution ribosome profiling dataset (Brar et al., 2012), we examined the timing of synthesis of all kinetochore components during meiotic progression by cluster analysis. This analysis revealed two major expression classes, one included kinetochore components that peak in expression prior to or during prophase I (early class), and the other contained components that instead show peak expression during the meiotic divisions (late class). The early class was enriched for inner kinetochore components (16 of 23), while the late class included primarily outer kinetochore components (13 of 18) (Figure 6B, Figure 6-figure supplements 1-10). The inner kinetochore binds to the centromere and generates a platform for the assembly of the outer kinetochore, which mediates microtubule attachments (Tanaka, 2010). The temporal difference in expression suggests that the inner kinetochore is assembled prior to the meiotic divisions, while the outer kinetochore is constructed only as cells enter the meiotic divisions.

Among the outer kinetochore components that displayed peak synthesis during the divisions, NDC80 and a subunit of the DASH complex, HSK3, displayed the most differential expression prior to meiosis I and during meiosis I, with a 9.02 and 2.64-fold induction, respectively (Figure 6B-D). This decline in $\mathrm{Ndc} 80$ expression is consistent with a previous study in fission yeast, showing that Ndc80 becomes undetectable at kinetochores during prophase I (Asakawa et al., 2005). Analysis of $\mathrm{Ndc} 80$ protein levels provided an explanation for why cells upregulate the synthesis of outer kinetochore components during entry into meiosis I. Ndc80 levels declined during premeiotic S phase and became undetectable during late prophase I (Figure 6E). Importantly, the ability of CUP-CLB3 to induce sister-chromatid segregation during meiosis I tightly correlated with Ndc80 protein levels; as $\mathrm{Ndc80}$ protein declines, so does CLB3-induced meiosis I sister chromatid segregation (compare Figure $6 A, E)$.

Hsk3 protein levels were also low until meiosis I entry (Figure 6F), but not all outer kinetochore components exhibited this decline in protein levels. For example, Ask1, a subunit of the DASH complex, was present throughout prophase I and levels of another DASH complex component, Dam1, increased during prophase I (Figure 6-figure supplement 11). Our findings indicate that the assembly of the outer kinetochore is restricted prior to NDT80 expression and pachytene exit due to low levels of a subset of outer kinetochore components.

\section{Expression of NDC80 and HSK3 during premeiotic S phase/prophase I enhances CLB3-induced meiosis I sister chromatid segregation}

To determine whether reduced expression of the outer kinetochore components Ndc80 and Hsk3 contributes to preventing premature microtubule-kinetochore engagement, we examined the consequences of expressing the two genes from the CUP1 promoter (Figure 7). We first assessed whether expression of the two proteins allows for the recruitment of the DASH complex to kinetochores, which occurs via delivery through microtubules and can thus be used as a means of assessing end-on attachment of kinetochores (Cheeseman et al., 2001; Tanaka, 2010). Cells were induced to sporulate and after $4 \mathrm{hr}$, a time when Ndc80 levels are normally diminished, we induced the expression of CLB3, NDC80 and/or HSK3. Whereas expression of either gene alone caused only a few cells to recruit Ask1 to kinetochores, cells simultaneously expressing NDC80, HSK3 and CLB3 during prophase I showed colocalization between Ask1 and the inner kinetochore component Ndc10, to an equal or greater extent than what was observed in metaphase l-arrested wild-type cells (Figure $8 \mathrm{~A}, \mathrm{~B}$ ). The difference in Ask1 localization was not due to a difference in ASK1 expression (Figure 8C). In addition, induction of CLB3 under the conditions mentioned above gave rise to bipolar spindles that appeared fragile with a weakened midzone. In contrast, consistent with stable microtubule-kinetochore interactions, coexpression of CLB3, HSK3 and NDC80 resulted in the formation of robust bipolar spindles (Figure 8D,E). Importantly, the expression of NDC80 and/or HSK3 during an NDT80 block caused a considerable 
A

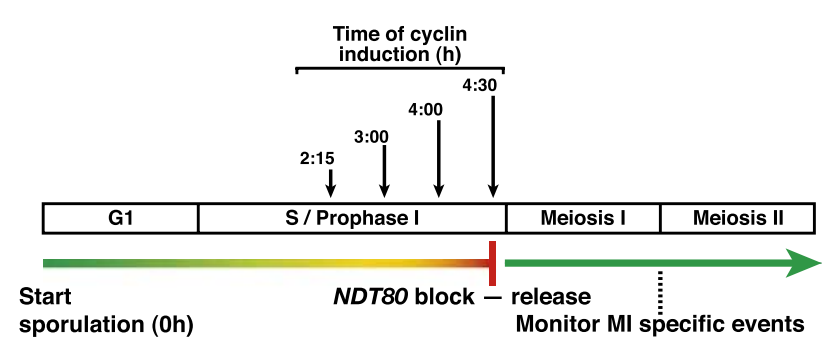

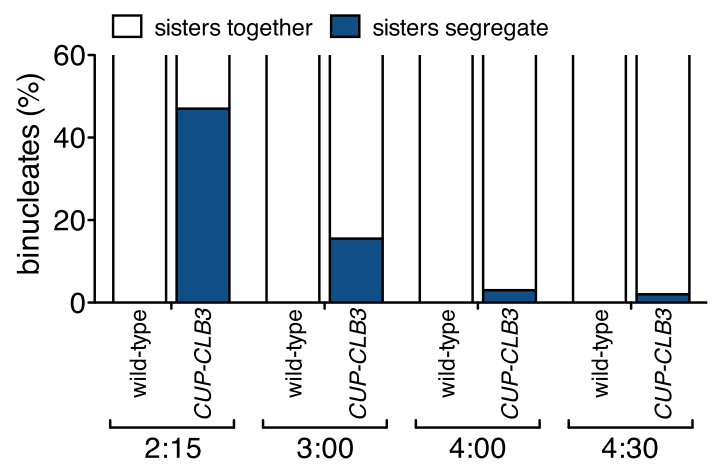

B

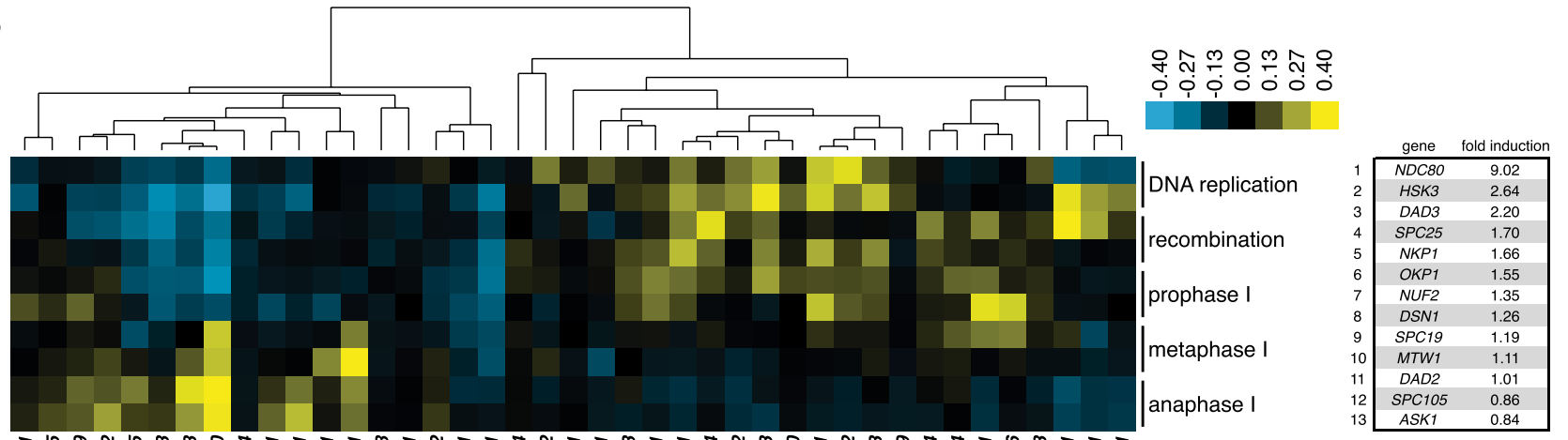

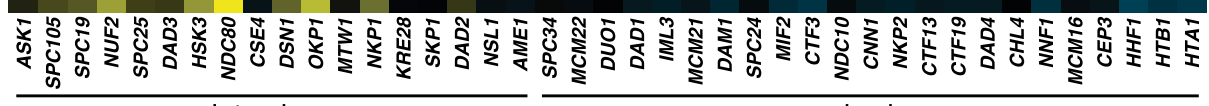

late class

C

C $\neg N D C 80$ mRNA

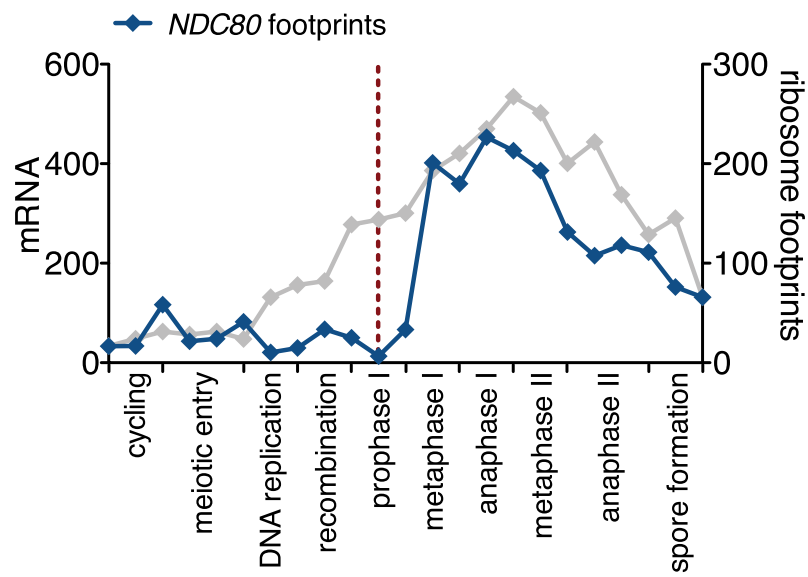

E

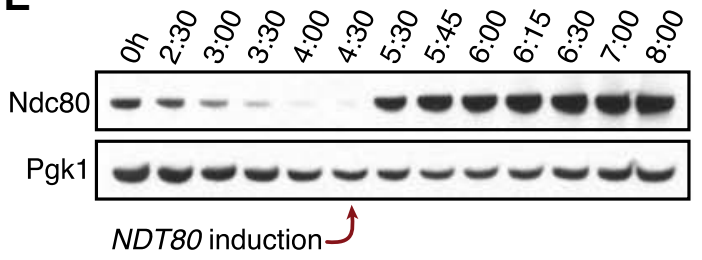

D $\rightarrow$ HSK3 mRNA

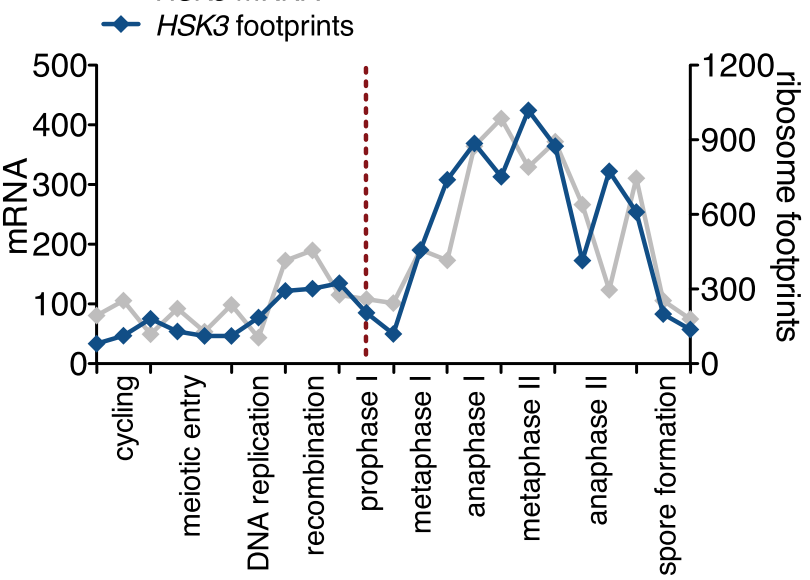

$\mathbf{F}$

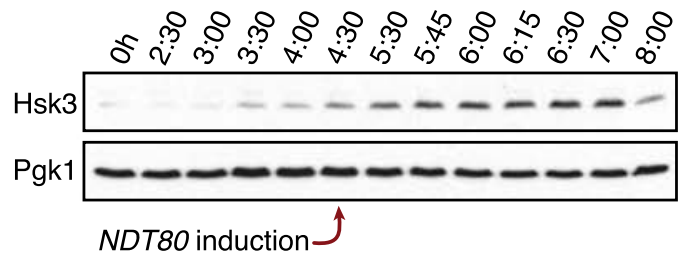

Figure 6. Meiosis I sister chromatid segregation correlates with presence of outer kinetochore components. (A) Schematic description of the experimental regime and segregation of sister chromatids using heterozygous CENV-GFP dots quantified in binucleates from wild-type (A22678) and CUP-CLB3 (A29406) after cyclin induction at $2 \mathrm{hr} 15 \mathrm{~min}, 3 \mathrm{hr}, 4 \mathrm{hr}$ and $4 \mathrm{hr} 30 \mathrm{~min}$ post transfer to sporulation medium. Cells released from NDT80 block at $4 \mathrm{hr} 30 \mathrm{~min}$ Figure 6. Continued on next page 
Figure 6. Continued

$(n=100)$. Using a chi-square test $(\mathrm{df} 1)$, the fraction of binucleates that display a reductional or equational division was compared between wild-type and CUP-CLB3 for each induction time point: (2:15), $X^{2}=58.00, p<0.0001 ;(3: 00), x^{2}=14.46, p=0.0001 ;(4: 00), x^{2}=1.020, p=0.3124 ;(4: 30), X^{2}=0.3384$, $p=0.5607$. (B) Cluster analysis of kinetochore components from the indicated time points. Further details are in the 'Materials and methods' and in Brar et al. (2012). Inner kinetochore = Cse4 nucleosomes, Cbf3, Ctf19 complexes and Mif2. Outer kinetochore = Spc105, Mis12, Ndc80 and DASH complexes. Fold induction is calculated by dividing the average expression from metaphase L —anaphase I by the average expression from DNA replicationprophase I. (C) Ordered plot for mRNA-seq and ribosome footprinting data for NDC80 and (D) HSK3 at the indicated stages. Dotted line indicates time of release from NDT80 block. Further details are in the 'Materials and methods' and in Brar et al. (2012). (E) Western blot for Ndc80-3V5 and Pgk1 from A30340 cells and (F) Hsk3-3V5 and Pgk1 from A31861 cells. Cells induced to sporulate and released from NDT80 block at 4 hr 30 min.

DOI: 10.7554/eLife.00117.039

The following figure supplements are available for figure 6 .

Figure supplement 1 . Schematic representation of the kinetochore-microtubule interface. DOI: 10.7554/eLife.00117.040

Figure supplement 2. Meiotic cluster analysis of kinetochore components.

DOI: 10.7554/eLife.00117.041

Figure supplement 3. Meiotic expression of DASH complex subunits. DOI: 10.7554/eLife.00117.042

Figure supplement 4. Meiotic expression of $\mathrm{Ndc} 80$ complex subunits. DOI: 10.7554/eLife.00117.043

Figure supplement 5. Meiotic expression of Mif2.

DOI: 10.7554/eLife.00117.044

Figure supplement 6. Meiotic expression of KNL-1 complex subunits. DOI: 10.7554/eLife.00117.045

Figure supplement 7. Meiotic expression of Mis12 complex subunits. DOI: 10.7554/eLife.00117.046

Figure supplement 8. Meiotic expression of Ctf19 complex subunits. DOI: 10.7554/eLife.00117.047

Figure supplement 9. Meiotic expression of $\mathrm{Cbf3}$ complex subunits. DOI: 10.7554/eLife.00117.048

Figure supplement 10. Meiotic expression of Histone subunits. DOI: 10.7554/eLife.00117.049

Figure supplement 11. Meiotic expression of Dam1 and Ask1. DOI: 10.7554/eLife.00117.050

increase in meiosis I sister chromatid segregation in CUP-CLB3 cells (Figure 8F). Furthermore, under conditions in which CLB3 expression alone failed to induce meiosis I sister chromatid segregation, expression of CLB3 together with NDC80 and HSK3 caused a substantial increase in meiosis I sister chromatid segregation (Figure $8 \mathrm{G}$ ). This occurred even when cells were maintained in a prolonged NDT80 block prior to expression of CLB3, NDC80 and HSK3 (Figure 9), ruling out the possibility that the expression of NDT80 targets, such as CDC5, early during sporulation contributes to sister chromatid segregation during meiosis I. We conclude that limiting outer kinetochore assembly is an additional mechanism to prevent microtubule-kinetochore interactions during premeiotic $\mathrm{S}$ phase and prophase I.

\section{Discussion}

The specialized chromosome segregation pattern in meiosis likely evolved through modifications of the mitotic cell division program. We find that preventing microtubule-kinetochore interactions during premeiotic S phase and prophase I is essential for transforming mitosis into meiosis I. Meiosis I chromosome morphogenesis, including the assembly of cohesin protective structures around centromeres and sister kinetochore coorientation, occurs during prophase I. We propose that when microtubules interact with kinetochores prior to completion of this remodeling process, they establish a default attachment, biorientation, which is incompatible with establishing sister kinetochore coorientation and a cohesin protective domain around centromeres (Figure 10). Our findings reveal a novel regulatory event that is essential for accurate meiosis I chromosome segregation and demonstrate that temporal restriction of microtubule-kinetochore interactions is instrumental in transforming mitosis into meiosis. 


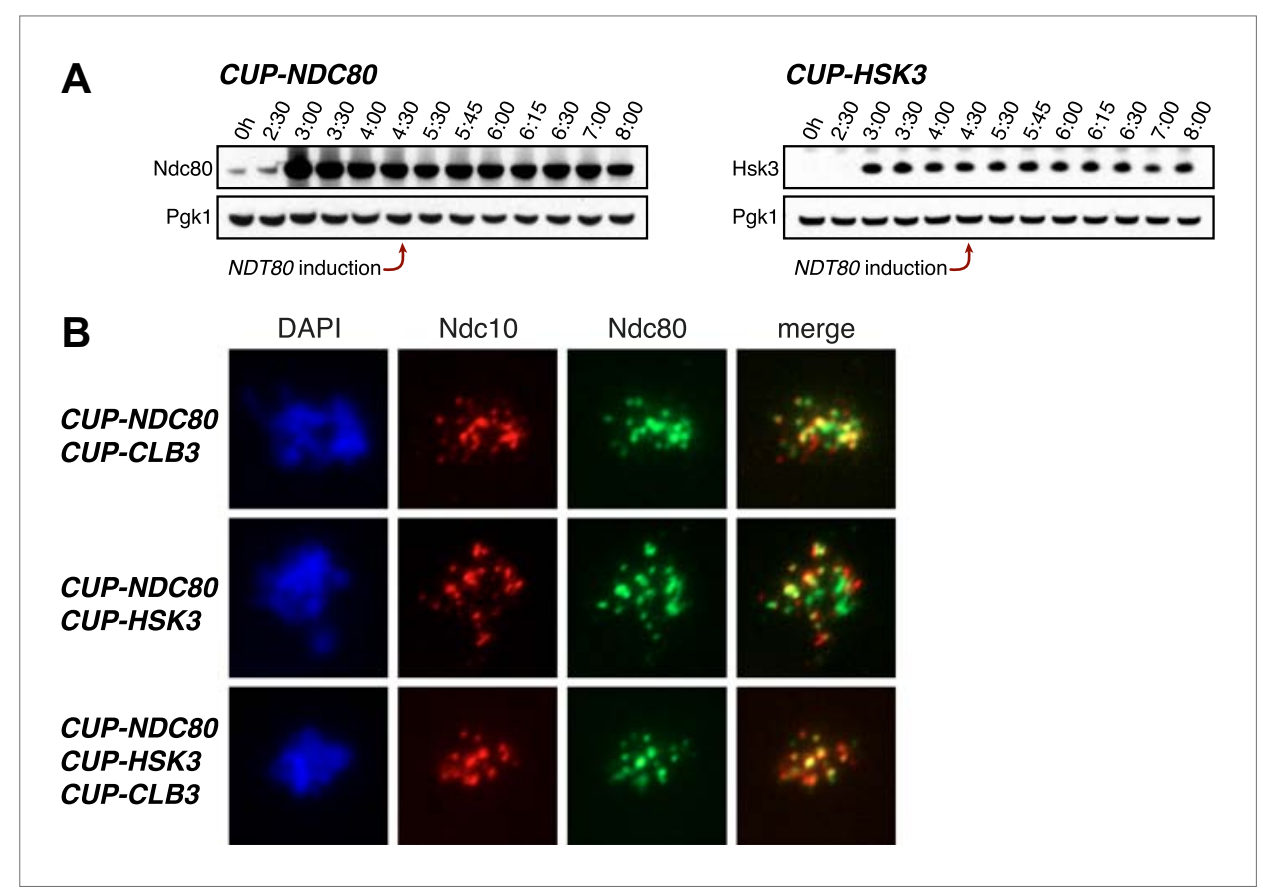

Figure 7. Characterization of NDC80 and HSK3 overexpression. (A) CUP-NDC80-3V5 (A30342) and CUP-HSK3-3HA (A32060) cells also carrying the GAL4-ER and GAL-NDT80 fusions were induced to sporulate. After $2 \mathrm{hr} 30 \mathrm{~min}$ $\mathrm{CuSO}_{4}(50 \mu \mathrm{M})$ was added and cells were subsequently released from NDT80 block $4 \mathrm{hr} 30 \mathrm{~min}$ after transfer into sporulation medium. The levels of Ndc80-3V5, Hsk3-3HA and Pgk1 were monitored by Western blot. (B) CUP-NDC80-3V5 CUP-CLB3 (A31949), CUP-NDC80-3V5 CUP-HSK3 (A31951) and CUP-NDC80-3V5 CUP-HSK3 CUP-CLB3 (A31953) cells were induced to sporulate. $4 \mathrm{hr}$ after transfer into sporulation medium $\mathrm{CuSO}_{4}(50 \mu \mathrm{M})$ was added, and localization of Ndc80-3V5 (green) relative to Ndc10-6HA (red) was determined by nuclear spreads $5 \mathrm{hr}$ after transfer into sporulation medium.

DOI: 10.7554/eLife.00117.051

\section{The effects of premature microtubule-kinetochore engagement on meiosis I chromosome morphogenesis}

Transcriptional and translational controls restrict CLB3 expression to meiosis II (Carlile and Amon, 2008). Eliminating both, by placing the gene under the control of the GAL1-10 promoter or the CUP1 promoter has dramatic effects on meiosis I chromosome segregation. CLB3 expression from the GAL1-10 promoter, which leads to Clb3 levels comparable to those seen for wild-type cells in meiosis II, causes a significant suppression of the meiosis I chromosome segregation pattern. This defect is not further enhanced by overexpression of the protein (by expression from the CUP1 promoter), which further indicates that this phenotype does not emanate from expressing exceedingly high levels of the cyclin, but is a consequence of premature expression.

The consequences of premature CLB3 expression are dramatic. It leads to premature microtubulekinetochore interactions and prevents coorientation factors from associating with kinetochores. The observation that the transient disruption of microtubule-kinetochore interactions, either by inactivating the outer kinetochore or by microtubule depolymerization, allowed coorientation factors to associate with kinetochores, despite CLB3 misexpression, led us to conclude that it is premature microtubulekinetochore interactions that interfere with the establishment of sister kinetochore coorientation during meiosis I. It is currently unclear how preexisting microtubule-kinetochore interactions prevent monopolin association with kinetochores. Precocious attachment of microtubules to kinetochores could occlude the monopolin complex from binding to kinetochores. Alternatively, tension between sister kinetochores generated from stable microtubule-kinetochore interactions could induce a conformational change at the kinetochore and/or pericentric chromatin such that coorientation factors can no longer associate with the kinetochore.

In addition to preventing sister kinetochore coorientation, premature expression of CLB3 interferes with protecting centromeric cohesin from removal during meiosis I. The same logic as outlined for 
A
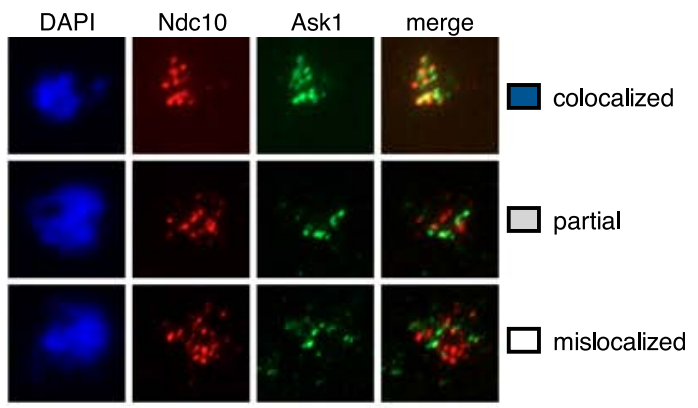

C

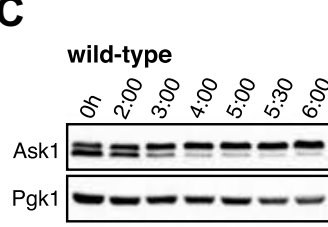

CUP-CLB3

CUP-NDC80

مَ CUP-HSK3
B

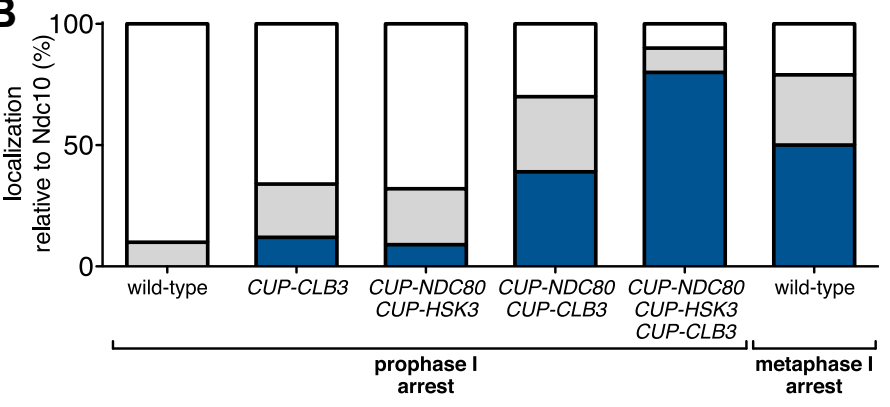

CUP-NDC80 CUP-CLB3
CUP-NDC80 CUP-HSK3 wild-type cdc20-mn
D

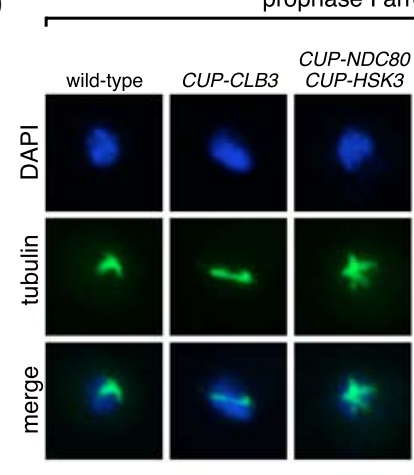

$\mathbf{F}$

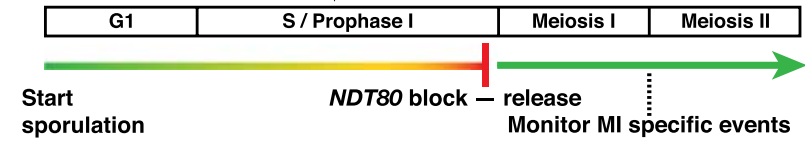

$\square$ sisters together $\square$ sisters segregate

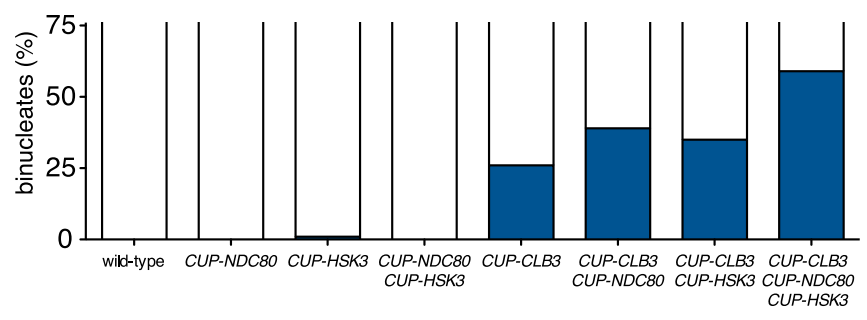

E
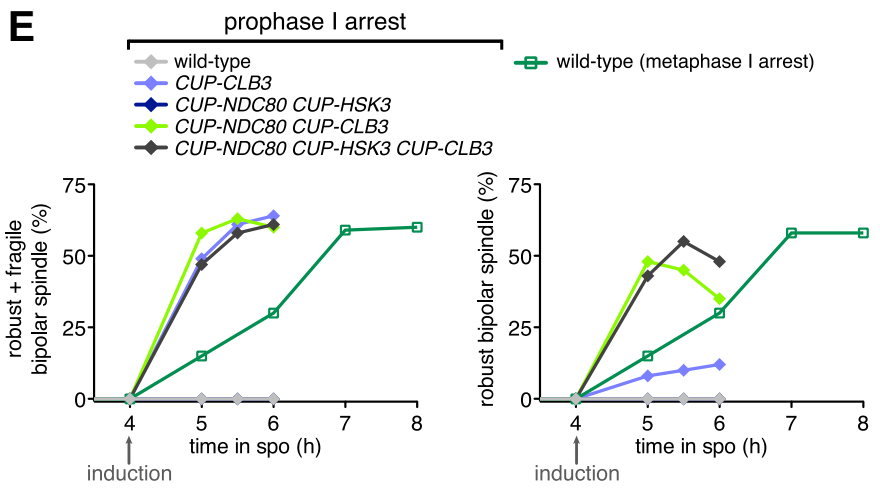

G

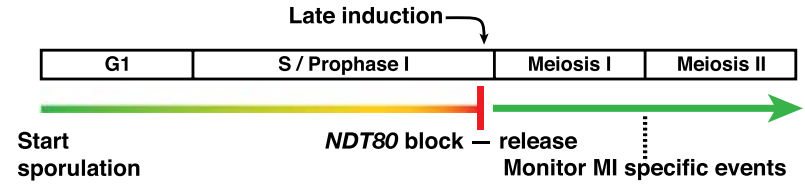

$\square$ sisters together $\square$ sisters segregate

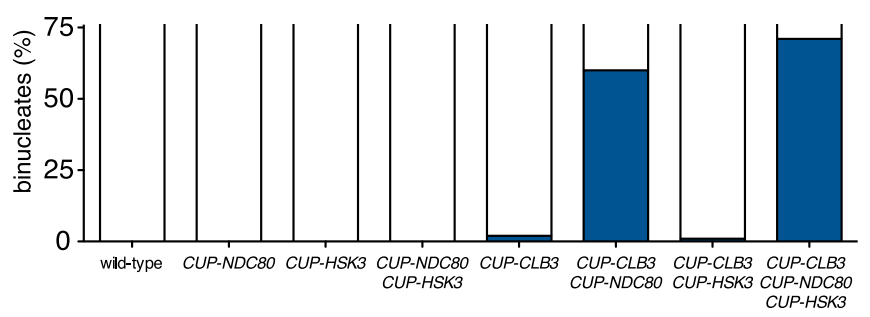

Figure 8. Expression of NDC80 and HSK3 in prophase I enhances Clb3-CDK-induced meiosis I sister chromatid segregation. For (A)-(E), wild-type (A31945), CUP-CLB3 (A31947), CUP-NDC80 CUP-HSK3 (A31951), CUP-NDC80 CUP-CLB3 (A31949), CUP-NDC80 CUP-HSK3 CUP-CLB3 (A31953) and cdc20-mn (A31955) cells were induced to sporulate and $\mathrm{CuSO}_{4}(50 \mu \mathrm{M})$ was added at $4 \mathrm{hr}$ after sporulation induction. (A) Representative images and (B) quantification of Ask1-13myc (green) in mononucleates relative to Ndc10-6HA (red) determined by nuclear spreads prepared after $1 \mathrm{hr}$ of $\mathrm{CuSO}_{4}$ induction ( $\mathrm{n}>40$ except for A31955 [n = 28]). For (B), using a chi-square test (df 2) the fraction of spread nuclei that display colocalized, partial or mislocalized Ask1 with respect to Ndc10 was compared between CUP-CLB3 and CUP-CLB3 CUP-NDC80 CUP-HSK3 $X^{2}=51.49, p<0.0001$. (C) Western blots of Ask1-13myc and Pgk1. (D) Bipolar spindle morphology and (E) left panel, total (robust + fragile) bipolar spindle formation, and right panel, robust bipolar spindle formation determined at the indicated time points (see 'Materials and methods' for further description) $(n=100$ per time point). Note: CUP-NDC80 CUP-HSK3 (dark blue) data points occluded by wild-type (grey) data points. (F), (G) Segregation of sister chromatids using Figure 8. Continued on next page 
heterozygous CENV-GFP dots quantified in binucleates from wild-type (A30340), CUP-NDC80 (A30342), CUP-HSK3 (A31849), CUP-NDC80 CUP-HSK3 (A31855), CUP-CLB3 (A31847), CUP-CLB3 CUP-NDC80 (A31853), CUP-CLB3 CUP-HSK3 (A31851) and CUP-CLB3 CUP-NDC80 CUP-HSK3 (A31857) (early induction $=2: 15 \mathrm{hr}$, late induction $=4: 30 \mathrm{hr}$ after induction of sporulation; release from NDT80 block at 4:30 hr) $(n=100)$. For $(\mathbf{F})$, using a chi-square test (df 1 ) the fraction of binucleates with a reductional or equational division was compared between CUP-CLB3 and CUP-CLB3 CUP-NDC80 CUP-HSK3 $X^{2}=22.28, p<0.0001$. For $(\mathbf{G})$, using a chi-square test ( $\mathrm{df} 1$ ) the fraction of binucleates with a reductional or equational division was compared between CUP-CLB3 and CUP-CLB3 CUP-NDC80 CUP-HSK3 $\mathrm{X}^{2}=102.7, \mathrm{p}<0.0001$.

coorientation factors applies to the conclusion that it is Clb3-CDK mediated premature microtubulekinetochore interactions that lead to loss of centromeric cohesin protection in CUP-CLB3 cells; disrupting microtubule-kinetochore interactions by various means restores stepwise loss of cohesin in CUP-CLB3 cells. A simple interpretation of this result is that the centromeric-cohesin protective domain can be disrupted by tension between sister kinetochores at any meiotic stage prior to anaphase I. This does not appear to be the case. In cells lacking the coorientation factor MAM1, sister kinetochores come under tension in metaphase l, yet in these cells centromeric cohesin is not removed prematurely (Toth et al., 2000 and Figure 4-figure supplement 3). Thus, the timing of microtubule-kinetochore interactions is of importance. It is tempting to speculate that the establishment of the centromericcohesin protective domain, which occurs during prophase I or perhaps even earlier, is sensitive to premature microtubule-kinetochore interactions and/or tension that promote biorientation of sister kinetochores. However, once this domain is established, its maintenance during meiosis I can no longer be disrupted by tension between sister kinetochores.

How premature microtubule-kinetochore interactions affect the centromeric cohesin protection machinery is not yet known. A defect in localization of the protective machinery to kinetochores does not appear to be the cause of this defect. Sgo1 and PP2A localize normally to kinetochores in CUP-CLB3 cells. Therefore, lack of cohesin protection upon premature microtubule-kinetochore engagement must either result from a defect in an unknown cohesin protection pathway or from a decrease in the activity of Sgo1 and/or PP2A. Premature association of kinetochores with microtubules could result in the untimely recruitment of a factor (e.g. Clb-CDKs themselves) to the pericentromere that inhibits the cohesin protective machinery. Alternatively, microtubule-kinetochore engagement could directly affect the activity of the protective machinery. Two mechanisms have been previously proposed whereby tension modulates the activity of the cohesin protective machinery. In mammalian cells, tension spatially separates centromeric cohesin from Sgo1-PP2A, perhaps leading to loss of protection (Lee et al., 2008). Tension has also been proposed to cause a deformation in PP2A, thus inhibiting its catalytic activity (Grinthal et al., 2010). Irrespective of whether it is tension-dependent perturbation of Sgo1-PP2A and/or recruitment of inhibitory factors, it is clear that premature microtubule-kinetochore engagement is a bona fide modulator of the cohesin protective machinery.

\section{Regulated kinetochore assembly contributes to preventing microtubule-kinetochore interactions}

Cyclin-CDKs regulate multiple aspects of microtubule-kinetochore dynamics. Cyclin-CDKs promote centrosome separation and bipolar spindle assembly (Fitch et al., 1992), kinetochore maturation (Holt et al., 2009) and chromosomal passenger complex localization (Tsukahara et al., 2010). Given the importance of preventing premature microtubule-kinetochore engagement to meiosis I chromosome morphogenesis, it is not surprising that cyclin-CDK activity is regulated at multiple levels in budding yeast; transcription of CLB1, CLB3 and CLB4 is not activated until cells exit pachytene (Chu and Herskowitz, 1998) and CLB3 translation is restricted to meiosis II (Carlile and Amon, 2008).

Cyclin-CDK activity is also tightly regulated in other eukaryotes. Metazoan oocytes arrest for an extended period of time in prophase I. Multiple mechanisms keep cyclin-CDK activity low to maintain this arrest (reviewed in Von Stetina and Orr-Weaver, 2011). Similar regulation is observed in D. melanogaster and C. elegans. Remarkably, inappropriate activation of Cyclin A or cyclin E during prophase I in fruit flies and worms, respectively, results in a mitosis-like division (Sugimura and Lilly, 2006; Biedermann et al., 2009). Thus, restricting cyclin-CDK activity during premeiotic $S$ phase and prophase I also appears to be required to establish a meiosis I-specific chromosome architecture in higher eukaryotes. 


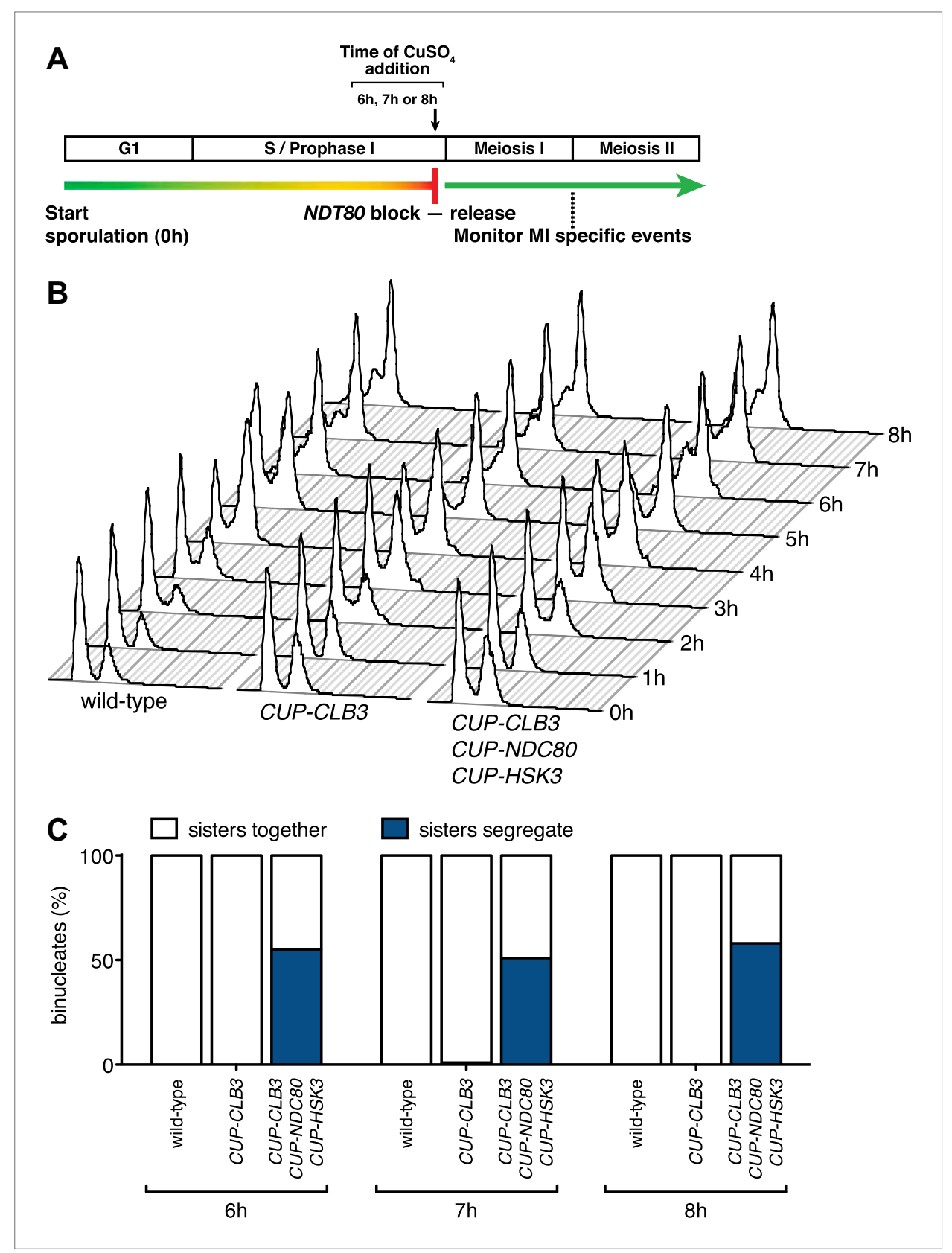

Figure 9. CUP-CLB3 CUP-NDC80 CUP-HSK3-induced meiosis I sister chromatid segregation is independent of the length of the prophase I arrest. (A) Schematic description of the experimental regime used in (B) and (C). (B), (C) Wild-type (A22678), CUP-CLB3 (A22702) and CUP-CLB3 CUP-NDC80 CUP-HSK3 (A31857) cells also carrying the GAL4-ER and GAL-NDT80 fusions were induced to sporulate. Cells were released from the NDT80 block and concurrently pCUP1-dependent expression was induced at either $6 \mathrm{hr}, 7 \mathrm{hr}$ or $8 \mathrm{hr}$ post transfer to sporulation medium (by addition of $1 \mu \mathrm{M}$ estradiol and $50 \mu \mathrm{M} \mathrm{CuSO}_{4}$ respectively). Samples were taken at the indicated time points to determine DNA content (B) and the percentage of binucleate cells with segregated sister chromatids (C). For (C), using a chi-square test (df 1), the fraction of binucleates that display a reductional or equational division in CUP-CLB3 CUP-NDC80 CUP-HSK3 cells was compared between $6 \mathrm{hr}$ and $7 \mathrm{hr}$ induction $\mathrm{X}^{2}=0.3212, \mathrm{p}=0.5709$ and between $6 \mathrm{hr}$ and $8 \mathrm{hr}$ induction $\mathrm{X}^{2}=0.1831, \mathrm{p}=0.6687$.

DOI: 10.7554/eLife.00117.053 
A

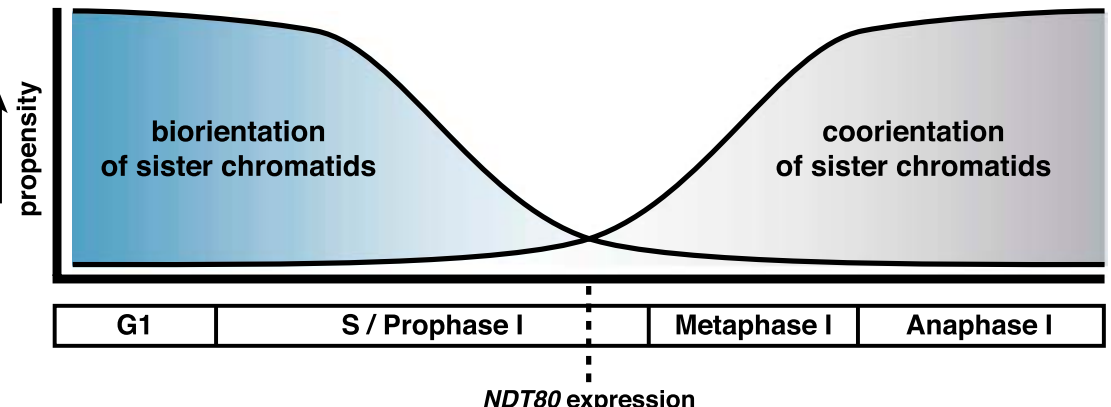

B

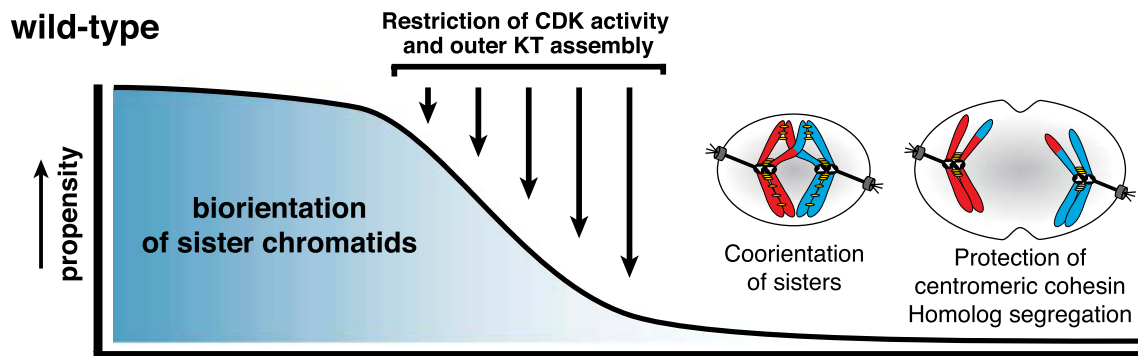

G1 $\quad$ S/Prophase I

\begin{tabular}{|l|l|l|l} 
Metaphase I & Anaphase I \\
\hline
\end{tabular}

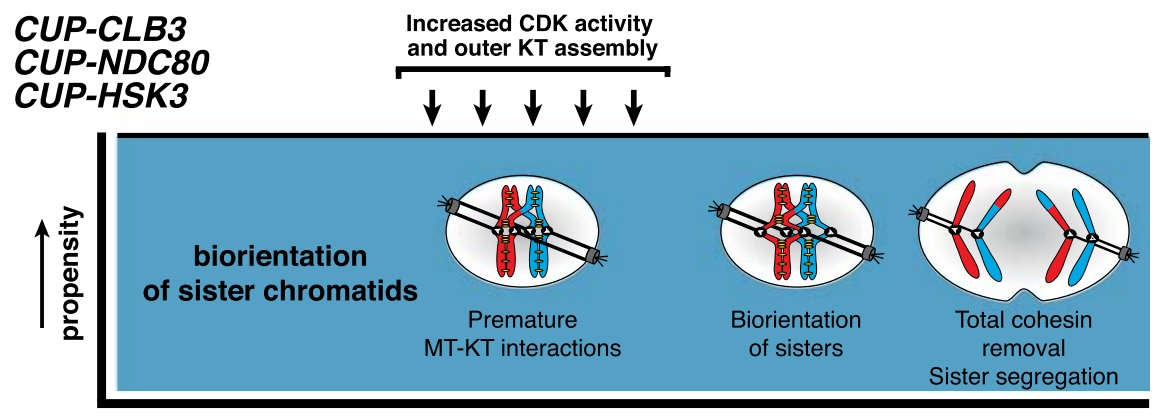

G1

S / Prophase I

\begin{tabular}{|l|l|l}
\hline Metaphase I & Anaphase I \\
\hline
\end{tabular}

Figure 10. Model for temporal regulation of microtubule-kinetochore interactions during meiosis. (A) As prophase I progresses, the propensity of sister chromatids to biorient decreases and the ability to coorient sister chromatids increases. (B) Top panel: inhibiting Clb-CDK activity and outer kinetochore (KT) assembly during prophase I establishes a meiosis I-specific chromosome segregation pattern by allowing sister kinetochore coorientation and protection of centromeric cohesin. Bottom panel: disrupting the regulation of microtubule-kinetochore (MT-KT) interactions causes sister chromatid segregation in meiosis I.

DOI: 10.7554/eLife.00117.054

Restriction of cyclin-CDK activity during premeiotic S phase and prophase I appears to be the major mechanism preventing premature microtubule-kinetochore interactions, but our data indicate that regulation of outer kinetochore assembly serves as an additional mechanism to prevent this from occurring. CUP-CLB3 can only induce meiosis I sister chromatid segregation when expressed during premeiotic $\mathrm{S}$ phase/early prophase I, but fails to do so when expressed during late prophase I. This difference is likely due to the outer kinetochore being present only until early prophase I. When $\mathrm{Ndc} 80, \mathrm{Hsk} 3$ and $\mathrm{Clb3}$ are coexpressed during late prophase I, sister chromatid segregation occurs in meiosis I. This result demonstrates that the presence of Clb3-CDKs alone during late prophase I is not sufficient to cause meiosis I sister chromatid segregation but that outer kinetochore 
components must also be expressed. Whether outer kinetochore disassembly solely occurs to prevent microtubule kinetochore interactions remains to be determined. Outer kinetochore disassembly could also serve additional purposes during prophase I such as enabling telomere-mediated chromosome movements. Further study of the kinetochore assembly/disassembly cycle during meiosis will provide insights into the full impact of kinetochore regulation on meiotic chromosome segregation.

In budding yeast, two essential components of the outer kinetochore, Ndc80 and Hsk3, are downregulated during prophase I. In S. pombe, $\mathrm{Ndc} 80$ and its binding partner Nuf2 dissociate from kinetochores in prophase I (Asakawa et al., 2005) raising the interesting possibility that deconstruction of the outer kinetochore is a conserved feature of meiotic prophase I. This dissociation depends on the mating pheromone signaling pathway (Asakawa et al., 2005). Intriguingly, ectopic induction of meiosis without mating pheromone signaling (i.e. in pat1 mutants), results in segregation of sister chromatids instead of homologous chromosomes in meiosis I (Yamamoto and Hiraoka, 2003; Yamamoto et al., 2004). Perhaps this change in the pattern of chromosome segregation in pat1 mutants arises from premature microtubule-kinetochore interactions due to a defect in outer kinetochore disassembly. Interestingly, in mouse oocytes, the Ndc80 complex is recruited to chromosomes only after nuclear envelope breakdown (Sun et al., 2011), raising the possibility that outer kinetochore assembly is also prevented in meiotic prophase I in vertebrates.

\section{Concluding remarks}

Proper segregation of the genome during gametogenesis is critical for the proliferation of sexually reproducing species. Errors in chromosome segregation during meiosis result in aneuploidy, the leading cause of birth defects and miscarriages in humans (Hassold and Hunt, 2001). Thus, it is crucial to understand how accurate meiotic chromosome segregation is achieved. We discovered that the establishment of a meiosis-specific chromosome segregation pattern depends on the regulation of microtubule-kinetochore interactions. This is achieved by regulating cyclin-CDK activity as well as assembly of the outer kinetochore. There is evidence for similar regulatory events across different organisms (Asakawa et al., 2005; Sugimura and Lilly, 2006; Biedermann et al., 2009; Von Stetina and Orr-Weaver, 2011), suggesting that temporal restriction of microtubule-kinetochore interactions is an evolutionarily conserved event required to execute proper meiotic chromosome segregation.

\section{Materials and methods}

\section{Strains and plasmids}

Strains used in this study are described in Supplementary file 1 and are derivatives of SK1 (all meiosis experiments) or W303 (Figure 5A). GAL-NDT80 and GAL4-ER constructs are described in Benjamin et al. (2003). CUP-CLB1, CUP-CLB3, CUP-CLB4, CUP-CLB5, SPC42-mCherry, SGO1-3V5, RTS1-13myc, RTS1-3V5, HSK3-3V5, NDC80-3V5, ASK1-13myc, CUP-NDC80-3V5, CUP-HSK3, mam14, SPO13-3V5, mad34, DAM1-3V5, CUP-HSK3-3HA were constructed by PCR-based methods described in Longtine et al. (1998). Primer sequences for strain constructions are available upon request. ndc80-1 and dam 1-1 are described in Wigge et al. (1998); Jones et al. (1999) and SK1 strains carrying these alleles were constructed via backcrossing (>9X). CENV-LacO was constructed by cloning a CENV homology region with Xhol restriction sites into the Sall cut plasmid pCM40 (gift from Doug Koshland) and integrated near CDEIII ( $<1 \mathrm{~kb}$ ) by BamHI digest. pHG40 carrying CUP1 promoter was a gift from Hong-Guo Yu. $3 \mathrm{~V} 5$ tagging plasmids were provided by Vincent Guacci.

\section{Sporulation conditions}

Strains were grown to saturation in YPD at room temperature, diluted in BYTA (1\% yeast extract, $2 \%$ tryptone, $1 \%$ potassium acetate, $50 \mathrm{mM}$ potassium phthalate) to $\mathrm{OD}_{600}=0.25$, and grown overnight at $30^{\circ} \mathrm{C}$ (room temperature for ndc80-1 and dam1-1 experiments). Cells were resuspended in sporulation medium ( $0.3 \%$ potassium acetate $[\mathrm{pH} 7], 0.02 \%$ raffinose) to $\mathrm{OD}_{600}=1.85$ and sporulated at $30^{\circ} \mathrm{C}$ unless otherwise indicated. GAL-NDT80 GAL4-ER strains were released from the NDT80 block by the addition of $1 \mu \mathrm{M} \beta$-estradiol (5 mM stock in ethanol; Sigma E2758-1G, St. Louis, MO) at $4 \mathrm{hr} 30 \mathrm{~min}$ unless otherwise indicated. Note: strains released from NDT80 block at $4 \mathrm{hr} 30 \mathrm{~min}$ are prototrophic and have accelerated meiotic kinetics relative to strains containing auxotrophies. Strains with CUP1 promoter 
driven alleles were induced by addition of $\mathrm{CuSO}_{4}(50 \mu \mathrm{M}$ final concentration; $100 \mathrm{mM}$ stock made from anhydrous powder [FW = $159.6 \mathrm{~g} / \mathrm{mol}]$; Mallinckrodt, Hazelwood, MO) at indicated times.

\section{Transient inactivation of the ndc80-1 or dam1-1 alleles}

Wild-type, ndc80-1 or dam1-1 cells carrying GAL-NDT80 GAL4-ER were induced to sporulate at room temperature (permissive temperature). After $2 \mathrm{hr} 45 \mathrm{~min}$, cyclin expression was induced by addition of $50 \mu \mathrm{M} \mathrm{CuSO}_{4}$ and cells were concurrently shifted to the semi-permissive $\left(34^{\circ} \mathrm{C}\right)$ or non-permissive $\left(>35.5^{\circ} \mathrm{C}\right)$ temperature and allowed to arrest in pachytene. Cells were then transferred to the permissive temperature and released from the NDT80 block by addition of $1 \mu \mathrm{M}$ $\beta$-estradiol into either a metaphase I arrest (by depleting $\mathrm{Cdc} 20$ ) or allowed to proceed through the meiotic divisions.

\section{Benomyl treatment of meiotic cultures}

Wild-type or CUP-CLB3 cells carrying the GAL-NDT80 GAL4-ER constructs were induced to sporulate at $30^{\circ} \mathrm{C} .2 \mathrm{hr} 15 \mathrm{~min}$ after transfer into sporulation medium, cells were filtered and transferred to medium containing $\mathrm{CuSO}_{4}(50 \mu \mathrm{M})$ and either $0.4 \%$ DMSO or benomyl $(120 \mu \mathrm{g} / \mathrm{ml})$. After an additional $2 \mathrm{hr} 15 \mathrm{~min}$ incubation, benomyl was washed out by filtering and washing cells with 10 volumes of sterile $\mathrm{dH}_{2} \mathrm{O}$ containing $0.4 \%$ DMSO. Cells were subsequently resuspended in sporulation medium containing $1 \mu \mathrm{M} \beta$-estradiol to release from NDT80 block. The efficacy of benomyl treatment was confirmed by spindle morphology. See Hochwagen et al. (2005) for further technical details regarding benomyl resuspension in sporulation medium.

\section{Mitotic induction of monopolin}

MATa haploid cells carrying the MET-CDC20 or MET-CDC20 GAL-CDC5 GAL-MAM1 fusions and CENIV-GFP dots cultured in complete synthetic medium without methionine (CSM-MET) containing $2 \%$ raffinose were arrested in $\mathrm{G} 1$ with $5 \mu \mathrm{g} / \mathrm{ml}$ a-factor. For Figure $5 \mathrm{~A}$ condition (1), cells were treated with galactose (to induce $\mathrm{Cdc} 5$ and Mam 1 production) for $1 \mathrm{hr}$ prior to $\alpha$-factor release. When arrest was complete, cells were released into rich medium (YEP) with $2 \%$ raffinose lacking pheromone and containing $2 \%$ galactose, $1 \%$ DMSO and $8 \mathrm{mM}$ methionine (to repress Cdc20 production). $8 \mathrm{mM}$ methionine was added every hour to maintain metaphase arrest. When metaphase arrest was complete, cells were released into CSM-MET medium, containing 2\% dextrose, $1 \%$ DMSO and $5 \mu \mathrm{g} / \mathrm{ml}$ a-factor. For condition (2), G1 arrested cells were released into YEP medium with $2 \%$ raffinose, lacking pheromone, containing $8 \mathrm{mM}$ methionine and 1\% DMSO. $8 \mathrm{mM}$ methionine was added every hour to maintain the metaphase arrest. After $2 \mathrm{hr}$, cells were treated with $2 \%$ galactose for $1 \mathrm{hr}$ and were subsequently released into CSM-MET medium, containing $2 \%$ dextrose, $1 \%$ DMSO and $5 \mu \mathrm{g} / \mathrm{ml}$ $\alpha$-factor. For condition (3), G1 arrested cells were released into YEP medium with $2 \%$ raffinose, lacking pheromone, containing $8 \mathrm{mM}$ methionine and $15 \mu \mathrm{g} / \mathrm{ml}$ nocodazole in DMSO. $8 \mathrm{mM}$ methionine was added every hour to maintain the metaphase arrest. After $2 \mathrm{hr}$, cells were treated with $2 \%$ galactose for $1 \mathrm{hr}$ and were subsequently released into CSM-MET medium, containing 2\% dextrose, 1\% DMSO and $5 \mu \mathrm{g} / \mathrm{ml} \alpha$-factor. Samples were taken every $15 \mathrm{~min}$ after release from metaphase arrest to determine GFP dot segregation in anaphase.

\section{Indirect immunofluorescence}

Indirect immunofluorescence was performed as described in Kilmartin and Adams (1984). Spindle morphologies were classified as follows: metaphase I or metaphase I-like spindles were defined as a short, bipolar spindle spanning a single DAPI mass. Anaphase I spindles were defined as an elongated spindle spanning two distinct DAPI masses. Metaphase II spindles were defined as two short, bipolar spindles, each spanning a DAPI mass. Anaphase II spindles were defined as two elongated spindles, each spanning two distinct DAPI masses (four DAPI masses total). For Figure 8D,E, robust bipolar spindle was classified as a short, thick, bipolar spindle with equal intensity tubulin staining across the entire length of the spindle. A fragile spindle was classified as a short bipolar spindle with lower intensity tubulin staining in the middle of the spindle axis.

\section{Live cell imaging}

Cells were induced to sporulate and $\mathrm{CuSO}_{4}$ was added at the indicated times. After 30-60 min post $\mathrm{CuSO}_{4}$ induction, cells were layered on a Concanavalin A ( $2 \mathrm{mg} / \mathrm{ml}$; stock solution $20 \mathrm{mg} / \mathrm{ml}$ diluted in $50 \mathrm{mM} \mathrm{CaCl}_{2}, 50 \mathrm{mM} \mathrm{MnSO}_{4}$ ) coated cover slip and assembled into an FCS2 fluidic chamber (Bioptechs 
Inc. Butler, PA). Sporulation medium was heated to $30^{\circ} \mathrm{C}$, aerated using an aquarium air pump (Petco Animal Supplies, Inc. Cambridge, MA) and was perfused into the fluidic chamber using a peristaltic pump (Gilson Inc., Middleton, WI) with a flow rate of 4-7 ml/h. Alternatively, cells were induced to sporulate as above and transferred to a microfluidic chamber (CellASIC Corp. Hayward, CA). Cells were imaged using a Zeiss Axio Observer-Z1 with a 100x objective (NA = 1.45), equipped with a Hamamatsu ORCA-ER digital camera. 11 Z-stacks (1 micron apart) were acquired and maximally projected. Metamorph software was used for image acquisition and processing. Images for Figure 2B was processed using Metamorph deconvolution software. For Figure 2C, a cell was scored as harboring a separated pair of sister kinetochores if the heterozygous CENV-GFP dot signal underwent transient splitting for at least two time points for the duration of the movie.

\section{GFP-dot and Spc42-mCherry cell fixation conditions}

An aliquot of cells was fixed with 3.7\% formaldehyde in $100 \mathrm{mM}$ phosphate buffer (pH 6.4) for 10-15 min. Cells were washed once with $100 \mathrm{mM}$ phosphate, 1.2 M sorbitol buffer ( $\mathrm{pH} 7.5)$ and permeabilized with $1 \%$ Triton X-100 stained with $0.05 \mu \mathrm{g} / \mathrm{ml}$ 4',6-diamidino-2-phenylindole (DAPI). Cells were imaged using a Zeiss Axioplan 2 microscope or a Zeiss Axio Observer-Z1 with a 100x objective (NA = 1.45), equipped with a Hamamatsu ORCA-ER digital camera. Openlab or Metamorph software was used for image acquisition and processing.

\section{Chromosome spreads}

$4 \mathrm{OD}_{600}$ units of cells were harvested and spheroplasted with $0.1 \mathrm{mg} / \mathrm{ml}$ zymolyase $100 \mathrm{~T}$ (Seikagaku Corp, Japan) and $15 \mathrm{mM}$ DTT in solution 1 (2\% potassium acetate, $0.8 \%$ sorbitol) for $10-13 \mathrm{~min}$ at $37^{\circ} \mathrm{C}$. Ice-cold solution 2 (100 mM MES [pH 6.4], $1 \mathrm{mM}$ EDTA, $0.5 \mathrm{mM} \mathrm{MgCl} 2,1 \mathrm{M}$ sorbitol) was added to stop spheroplasting and cells were centrifuged at $2500 \mathrm{rpm}$ for 2-3 min. The supernatant was discarded and the pellet was gently resuspended in 100-200 $\mu$ l of solution $2.15 \mu \mathrm{l}$ of the resuspension was spread onto a glass slide. Subsequently, $30 \mu \mathrm{l}$ of fixative solution (4\% paraformaldehyde, $3.4 \%$ sucrose), $60 \mu \mathrm{l}$ of $1 \%$ lipsol and $60 \mu \mathrm{l}$ of fixative solution were added on top of cell suspension and spread using a glass rod seven to ten times back and forth. The slides were dried for at least $2 \mathrm{hr}$ at room temperature, rehydrated in PBS pH 7.4, blocked with $0.2 \%$ gelatin, $0.5 \%$ BSA in PBS, and stained as described in the 'Antibody' section. For quantifications of spread nuclei, images were acquired using a Zeiss Axioplan 2 microscope or a Zeiss Axio Observer-Z1 with a 100x objective (NA = 1.45), equipped with a Hamamatsu ORCA-ER digital camera. Openlab or Metamorph software was used for image acquisition and processing. 40-100 spread nuclei were counted for each sample, except for strain A31955 in Figure 8B $(n=28)$. Two proteins were identified as colocalized in spread nuclei when more than $90 \%$ of foci overlapped. They were defined as partially colocalized when the overlap between foci was approximately $50 \%$ and as mislocalized when the overlap was negligible.

\section{In vitro kinase assay}

In vitro kinase assays were performed as described in Carlile and Amon (2008) with the following modifications: $1 \mathrm{mg}$ of total protein was incubated with $40 \mu \mathrm{l}$ of $50 \%$ slurry anti-V5 agarose affinity gel (Sigma, St. Louis, MO) for $2 \mathrm{hr}$ at $4^{\circ} \mathrm{C}$. One half of the immunoprecipitate was used for the in vitro kinase assay, while the other half was used for Western blotting to detect Cdc28-3V5.

\section{Western blot analysis}

For immunoblot analysis, $\sim 10 \mathrm{OD}_{600}$ units of cells were harvested and treated with $5 \%$ trichloroacetic acid for at least $10 \mathrm{~min}$ at $4^{\circ} \mathrm{C}$. The acid was washed away with acetone and the cell pellet was subsequently dried. The cell pellet was pulverized with glass beads in $100 \mu \mathrm{L}$ of lysis buffer $(50 \mathrm{mM}$ Tris- $\mathrm{HCl}$ at $\mathrm{pH}$ 7.5, $1 \mathrm{mM}$ EDTA, $2.75 \mathrm{mM}$ DTT, complete protease inhibitor cocktail [Roche, Basel, Switzerland]) using a bead-beater (Biospec Products, Inc. Bartlesville, OK). 3× SDS sample buffer was added and the cell homogenates were boiled. Standard procedures for sodium dodecyl sulfate-polyacrylamide gel electrophoresis (SDS-PAGE) and Western blotting were followed (Laemmli, 1970; Towbin et alı, 1979; Burnette, 1981). A nitrocellulose membrane (VWR International LLC, Radnor, PA) was used to transfer proteins from polyacrylamide gels. Antibody dilutions are described in the 'Antibody' section.

\section{Flow cytometry}

$1 \mathrm{ml}$ aliquot of a meiotic culture was spun down and the pellet was re-suspended in $70 \%$ ethanol and fixed for at least $60 \mathrm{~min}$. Ethanol was removed and the cell pellet was washed with $50 \mathrm{mM}$ 
sodium citrate, $\mathrm{pH} 7$ and sonicated for $6 \mathrm{~s}$ at $50 \%$ output. The sample was subsequently incubated with $0.25 \mathrm{mg} / \mathrm{ml}$ Ribonuclease A (Sigma, St. Louis, MO) in $50 \mathrm{mM}$ sodium citrate overnight at $37^{\circ} \mathrm{C}$, washed once with $50 \mathrm{mM}$ sodium citrate and re-suspended in $50 \mathrm{mM}$ sodium citrate with either $1 \mu \mathrm{M}$ Sytox Green (Molecular Probes, Carlsbad, CA) or $16 \mu \mathrm{g} / \mathrm{ml}$ propidium iodide (Sigma). Samples were analyzed using FACSCalibur (Becton Dickenson Co. Franklin Lakes, NJ).

\title{
Chromatin immunoprecipitation
}

$400 \mathrm{OD}_{600}$ units of cells were fixed for $15 \mathrm{~min}$ at room temperature in $1 \%$ formaldehyde. The formaldehyde was quenched by addition of $125 \mathrm{mM}$ glycine. Samples were processed as previously described (Vader et al., 2011). Before immunoprecipitation, 120th of the sample was removed as the input sample. The antibodies used for immunoprecipitation are described in the 'Antibody' section. For ChIP-chip, samples were processed and analyzed as described in Vader et al. (2011). For qPCR analysis, DNA was amplified using SYBR Premix ExTaq Perfect Real Time Kit (Takara Bio Inc. Otsu, Shiga, Japan). PCR reactions were 40 cycles of $95^{\circ} \mathrm{C}, 20 \mathrm{~s} ; 55^{\circ} \mathrm{C}, 30 \mathrm{~s} ; 72^{\circ} \mathrm{C}, 30 \mathrm{~s}$ using a Roche LightCycler 480 II (Roche, Basel, Switzerland). The following primers were used (5'-3'):

\author{
CENV F: CTT GTT TAG TGC AAG CCA CTG TT \\ CENV R: CCG CAT TTC CTT GAT TTA CTG TC \\ c281 F: CAA CGA ACC GTG GGA ACG TTA TAG \\ c281 R: GAA ACT TTC CTG GTA CCT TCT GC \\ c194 F: GCT GAA AGC ATG CCA CTG TA \\ c194 R: GGT GTT CCT GCT TCG TTG TTA G \\ HMR F: ACG ATC CCC GTC CAA GTT ATG \\ HMR R: CTT CAA AGG AGT CTT AAT TTC CCT G
}

\section{Recombination southern}

$\sim 20 \mathrm{OD}_{600}$ units of cells were harvested and treated with sodium azide $(0.1 \%$ final concentration). Cells were pelleted and snap frozen in liquid nitrogen. Genomic DNA was extracted as follows: Cells were washed once in TE and spheroplasted with 1/100 volume of beta-mercaptoethanol and $250 \mathrm{\mu g} / \mathrm{ml}$ zymolyase T100 in spheroplasting buffer (1 M sorbitol, $42 \mathrm{mM} \mathrm{K}{ }_{2} \mathrm{HPO}_{4}, 8 \mathrm{mM} \mathrm{KH}_{2} \mathrm{PO}_{4}$, $5 \mathrm{mM}$ EDTA) for $30 \mathrm{~min}$ at $37^{\circ} \mathrm{C}$ on a rotating rack. $100 \mu \mathrm{l}$ preheated $\left(65^{\circ} \mathrm{C}\right)$ lysis buffer $(1: 1 \mathrm{mix}$ of $1 \mathrm{M}$ Tris $\mathrm{pH} 8$ and $0.5 \mathrm{M}$ EDTA, 2.5-3\% SDS) was added and mixed by inverting. $15 \mu$ proteinase $\mathrm{K}$ (18 $\pm 4 \mathrm{mg} / \mathrm{ml} \mathrm{PCR}$ grade solution; Roche, Basel, Switzerland) was added and incubated at $65^{\circ} \mathrm{C}$ for $\sim 1.5 \mathrm{hr}$. Subsequently, $150 \mu \mathrm{l} 5 \mathrm{M}$ potassium acetate was added, mixed by inverting and transferred to $4^{\circ} \mathrm{C}$ for $10 \mathrm{~min}$. Samples were centrifuged at $4^{\circ} \mathrm{C}$ for $20 \mathrm{~min}$ and $650 \mu \mathrm{l}$ of supernatant was transferred into a $2 \mathrm{ml}$ tube containing $750 \mu \mathrm{l} 100 \%$ ethanol, avoiding as much of the white fluff as possible. Samples were mixed by inverting and left at $4^{\circ} \mathrm{C}$ for $10 \mathrm{~min}$. Nucleic acid was precipitated at $15,000 \mathrm{rpm}$ for $10 \mathrm{~min}, 4^{\circ} \mathrm{C}$. Samples were subsequently resuspended in TE and treated with RNase A (50 $\mathrm{gg} / \mathrm{ml}$; Roche), for $15-20 \mathrm{~min}$ at $37^{\circ} \mathrm{C}$ and kept at $4^{\circ} \mathrm{C}$ overnight. DNA was extracted with phenol/chloroform/isopropanol and was resuspended in $125 \mu \mathrm{lTE}$. Xhol-Mlul digested DNA fragments were separated on $0.6 \%$ agarose gel in $1 \times$ TBE and transferred onto Hybond-XL plus membranes (GE Healthcare Biosciences, Pittsburgh, PA) by alkaline transfer. Southern blotting was performed as previously described (Hunter and Kleckner, 2001).

\section{Antibodies}

Indirect immunofluorescence

Spindle morphology was determined using a rat anti-tubulin antibody (Serotec, Kidlington, UK) used at a dilution of 1:100, and anti-rat FITC antibodies (Jackson ImmunoResearch Laboratories, Inc. West Grove, PA) used at a dilution of 1:100-200.

\section{Western blotting}

Lrs4-13myc, Rec8-13myc, Ask1-13myc and Mam1-9myc were detected using a mouse anti-myc antibody (Covance, Princeton, NJ) at a 1:500 dilution. Rec8-3HA and Hsk3-3HA were detected using a mouse anti-HA antibody (HA.11; Covance) at a 1:1000 dilution. Hsk3-3V5, Ndc80-3V5 and Dam1-3V5 were detected using a mouse anti-V5 antibody (Invitrogen, Carlsbad, CA) at a 1:2000 dilution. Pgk1 was detected using a mouse anti-Pgk1 antibody (Molecular Probes, Carlsbad, CA) at a 
1:10,000 dilution. Clb3 was detected using a rabbit anti-Clb3 antibody (Sc7167; Santa Cruz Biotechnology Inc. Santa Cruz, CA) at a 1:500 dilution. Kar2 was detected using a rabbit anti-Kar2 antibody (kindly provided by Mark Rose) at a 1:200,000 dilution. The secondary antibodies used were a sheep antimouse antibody conjugated to horseradish peroxidase (HRP) (GE Healthcare Biosciences, Pittsburgh, PA) at a 1:5000 dilution or a goat anti-rabbit antibody conjugated to HRP (BioRad, Hercules, CA) at a 1:10,000 dilution. Antibodies were detected using the SuperSignal West Pico Chemiluminescent Substrate (Thermo Scientific, Waltham, MA).

\section{Chromatin immunoprecipitation}

Rec8-3HA was immunoprecipitated using 2-5 $\mu \mathrm{g}$ of rat anti-HA antibody (3F10; Roche, Basel, Switzerland) in combination with $50 \mu \mathrm{l}$ of $50 \%$ slurry Protein G beads (Roche). Rec $8-13$ myc was immunoprecipitated using 2-5 $\mu \mathrm{g}$ of mouse anti-myc antibody (9E11) in combination with $50 \mu \mathrm{l}$ of $50 \%$ slurry Protein G beads (Roche). Sgo1-3V5 and Spo13-3V5 were immunoprecipitated with $40-50 \mu$ of $50 \%$ slurry anti-V5 agarose affinity gel (Sigma, St. Louis, MO). Pds 5 was immunoprecipitated using $1.3 \mu \mathrm{l}$ of rabbit anti-Pds5 antibody (kindly provided by Vincent Guacci) in combination with $50 \mu \mathrm{l}$ of $50 \%$ slurry Protein A beads (Roche). Phosphorylated Rec 8 was immunoprecipitated using $2 \mu \mathrm{g}$ of rabbit anti-phospho-S179 Rec8 or rabbit anti-phospho-S521 Rec8 in combination with $50 \mu$ l of $50 \%$ slurry Protein A beads (Roche).

\section{Chromosome spreads}

Lrs4-13myc, Ndc10-13myc, Sgo1-9myc, Rts1-13myc, Rec8-13myc, Ask1-13myc, and Mam1-9myc were detected using a preabsorbed rabbit anti-myc antibody (Gramsch, Schwabhausen, Germany) at a 1:400 dilution. Ndc10-6HA and Rec8-3HA were detected using either a preabsorbed mouse anti-HA antibody (HA.11; Covance, Princeton, NJ) or a rat anti-HA antibody (3F10; Roche, Basel, Switzerland) at a 1:400 dilution. Ndc80-3V5 was detected using a mouse anti-V5 antibody (Invitrogen, Carlsbad, CA) at a 1:400 dilution. Zip1 was detected using y-300 rabbit antibody (Santa Cruz Biotechnology Inc. Santa Cruz, CA) at a 1:400 dilution. Rad51 was detected using y-180 rabbit IgG (Santa Cruz Biotechnology Inc.) at a 1:400 dilution. Secondary antibodies used were preabsorbed anti-rabbit FITC antibody (Jackson ImmunoResearch Laboratories, Inc. West Grove, PA), preabsorbed anti-rat CY3 antibody (Jackson ImmunoResearch Laboratories, Inc.) or preabsorbed anti-mouse CY3 antibody (Jackson ImmunoResearch Laboratories, Inc.) at a 1:400-1:800 dilution.

\section{Cluster analysis and ordered plots for mRNA-seq and ribosome footprinting data}

Cluster analysis of the ribosome footprinting data for the kinetochore components listed in Figure 6figure supplement 1 was performed using Cluster 3.0. Genes were clustered by hierarchical average based on Spearman correlation using mean centered arrays. Clustering data (Figure 6B, Figure 6figure supplement 2) were visualized using Java Treeview. Note that ribosome footprints are normalized such that the sum of expression across the time course is equivalent for each gene. For plots in Figure $6 C, D$ and Figure 6 -figure supplements 3-10, mRNA-seq and ribosome footprinting data were plotted for indicated genes based on the dataset from Brar et al. (2012). The meiotic stages plotted on the $x$-axis are in the following order: vegetative (gb15 exponential and A14201 exponential), meiotic entry ( $1, A, B$ and $D)$, DNA replication (E and F), recombination ( $G$ and I), prophase I ( 3 and 4$)$, metaphase I ( 5 and 6), anaphase I (7 and 8), metaphase II (9 and 10), anaphase II (11, 12 and 13) and spore formation (15 and 18). The detailed explanation of the above letter and number codes can be found in Brar et al. (2012).

\section{Statistical analysis}

Chi-square $\left(X^{2}\right)$ tests were performed using GraphPad Prism 6.0 software with two-tailed $P$ values and $95 \%$ confidence intervals. Corresponding degrees of freedom (df), $X^{2}$ and $P$ values are shown in the figure legends.

\section{Acknowledgements}

We are grateful to Hong-Guo Yu, Vincent Guacci, and Wolfgang Zachariae for reagents, Hannah Blitzblau, Gerben Vader, Jingxun Chen, Kristin Kuhn, Kristin Knouse, Ann Thompson, André and Charles Felts for technical assistance, Steve Bell, Leon Chan, Dean Dawson, Doug Koshland, Andrew Murray, Terry Orr-Weaver and members of the Amon lab for their critical reading of this manuscript. 


\section{Additional information}

\begin{tabular}{ll} 
Funding & Grant reference \\
Funder & Author \\
\hline $\begin{array}{l}\text { Howard Hughes } \\
\text { Medical Institute }\end{array}$ & $\begin{array}{l}\text { Matthew P Miller, Elçin Ünal, } \\
\text { Gloria A Brar, Angelika Amon }\end{array}$ \\
$\begin{array}{l}\text { National Institutes } \\
\text { of Health }\end{array}$ & $\begin{array}{l}\text { Matthew P Miller, Elçin Ünal, } \\
\text { Gloria A Brar, Angelika Amon }\end{array}$ \\
$\begin{array}{l}\text { Jane Coffin Childs } \\
\text { Memorial Fund }\end{array}$ & EM62207 \\
$\begin{array}{ll}\text { American Cancer } \\
\text { Society }\end{array}$ & Gloria A Brar \\
\hline
\end{tabular}

The funders had no role in study design, data collection and interpretation, or the decision to submit the work for publication.

Author contributions

MPM, Conception and design, Acquisition of data, Analysis and interpretation of data, Drafting or revising the article; EÜ, Conception and design, Acquisition of data, Analysis and interpretation of data, Drafting or revising the article; GAB, Acquisition of data, Analysis and interpretation of data, Drafting or revising the article; AA, Conception and design, Analysis and interpretation of data, Drafting or revising the article

\section{Additional files}

Supplementary files

- Supplementary file 1. Strains used in this study.

DOI: 10.7554/eLife.00117.055

Major datasets

The following datasets were generated

\begin{tabular}{|c|c|c|c|c|}
\hline Author(s) & Year & Dataset title & $\begin{array}{l}\text { Dataset ID } \\
\text { and/or URL }\end{array}$ & $\begin{array}{l}\text { Database, license, and } \\
\text { accessibility information }\end{array}$ \\
\hline $\begin{array}{l}\text { Miller MP, Ünal E, } \\
\text { Brar GA, Amon A }\end{array}$ & 2012 & $\begin{array}{l}\text { Mapping of cohesion } \\
\text { factor association sites in } \\
\text { S. cerevisiae-Meiosis I } \\
\text { chromosome segregation is } \\
\text { established through regulation } \\
\text { of microtubule-kinetochore } \\
\text { interactions }\end{array}$ & $\begin{array}{l}\text { GSE41339; http:// } \\
\text { www.ncbi.nlm.nih. } \\
\text { gov/geo/query/acc. } \\
\text { cgi?acc=GSE41339 }\end{array}$ & Publicly available at GEO \\
\hline
\end{tabular}

\section{References}

Asakawa H, Hayashi A, Haraguchi T, Hiraoka Y. 2005. Dissociation of the Nuf2-Ndc80 complex releases centromeres from the spindle-pole body during meiotic prophase in fission yeast. Mol Biol Cell 16:2325-38. doi: 10.1091/mbc.E04-11-0996.

Benjamin KR, Zhang C, Shokat KM, Herskowitz I. 2003. Control of landmark events in meiosis by the CDK Cdc28 and the meiosis-specific kinase Ime2. Genes Dev 17:1524-39. doi: 10.1101/gad.1101503.

Biedermann B, Wright J, Senften M, Kalchhauser I, Sarathy G, Lee MH. 2009. Translational repression of cyclin E prevents precocious mitosis and embryonic gene activation during C. elegans meiosis. Dev Cell 17:355-64. doi: 10.1016/j.devcel.2009.08.003.

Blitzblau H, Chan C, Hochwagen A, Bell S. 2012. Separation of DNA replication from the assembly of break-competent meiotic chromosomes. PLoS Genet 8:e1002643.

Brar GA, Kiburz BM, Zhang Y, Kim JE, White F, Amon A. 2006. Rec8 phosphorylation and recombination promote the step-wise loss of cohesins in meiosis. Nature 441:532-6. doi: 10.1038/nature04794.

Brar GA, Yassour M, Friedman N, Regev A, Ingolia NT, Weissman JS. 2012. High-resolution view of the yeast meiotic program revealed by ribosome profiling. Science 335:552-7. doi: 10.1126/science.1215110.

Buonomo SB, Clyne RK, Fuchs J, Loidl J, Uhlmann F, Nasmyth K. 2000. Disjunction of homologous chromosomes in meiosis I depends on proteolytic cleavage of the meiotic cohesin Rec8 by separin. Cell 103:387-98. 
Burnette WN. 1981. "Western blotting": electrophoretic transfer of proteins from sodium dodecyl sulfatepolyacrylamide gels to unmodified nitrocellulose and radiographic detection with antibody and radioiodinated protein A. Anal Biochem 112:195-203.

Carlile TM, Amon A. 2008. Meiosis I is established through division-specific translational control of a cyclin. Cell 133:280-91. doi: 10.1016/j.cell.2008.02.032.

Cheeseman IM, Enquist-Newman M, Muller-Reichert T, Drubin DG, Barnes G. 2001. Mitotic spindle integrity and kinetochore function linked by the Duo1p/Dam1p complex. J Cell Biol 152:197-212.

Chu S, Herskowitz I. 1998. Gametogenesis in yeast is regulated by a transcriptional cascade dependent on Ndt80. Mol Cell 1:685-96.

Ciosk R, Zachariae W, Michaelis C, Shevchenko A, Mann M, Nasmyth K. 1998. An ESP1/PDS1 complex regulates loss of sister chromatid cohesion at the metaphase to anaphase transition in yeast. Cell 93:1067-76.

Clyne RK, Katis VL, Jessop L, Benjamin KR, Herskowitz I, Lichten M. 2003. Polo-like kinase Cdc5 promotes chiasmata formation and cosegregation of sister centromeres at meiosis I. Nat Cell Biol 5:480-5. doi: $10.1038 /$ ncb977.

Cohen-Fix O, Peters JM, Kirschner MW, Koshland D. 1996. Anaphase initiation in Saccharomyces cerevisiae is controlled by the APC-dependent degradation of the anaphase inhibitor Pds1p. Genes Dev 10: 3081-93.

Fitch I, Dahmann C, Surana U, Amon A, Nasmyth K, Goetsch L. 1992. Characterization of four B-type cyclin genes of the budding yeast Saccharomyces cerevisiae. Mol Biol Cell 3:805-18.

Grandin N, Reed SI. 1993. Differential function and expression of Saccharomyces cerevisiae B-type cyclins in mitosis and meiosis. Mol Cell Biol 13:2113-25.

Grinthal A, Adamovic I, Weiner B, Karplus M, Kleckner N. 2010. PR65, the HEAT-repeat scaffold of phosphatase PP2A, is an elastic connector that links force and catalysis. Proc Natl Acad Sci USA 107:2467-72. doi: 10.1073/ pnas.0914073107.

Hassold T, Hunt P. 2001. To err (meiotically) is human: the genesis of human aneuploidy. Nat Rev Genet 2:280-91. doi: 10.1038/35066065.

Hochwagen A, Wrobel G, Cartron M, Demougin P, Niederhauser-Wiederkehr C, Boselli MG. 2005. Novel response to microtubule perturbation in meiosis. Mol Cell Biol 25:4767-81. doi: 10.1128/ MCB.25.11.4767-4781.2005.

Holt LJ, Tuch BB, Villen J, Johnson AD, Gygi SP, Morgan DO. 2009. Global analysis of Cdk1 substrate phosphorylation sites provides insights into evolution. Science 325:1682-6. doi: 10.1126/science.1172867.

Hunter N, Kleckner N. 2001. The single-end invasion: an asymmetric intermediate at the double-strand break to double-holliday junction transition of meiotic recombination. Cell 106:59-70.

Jones MH, Bachant JB, Castillo AR, Giddings TH Jnr, Winey M. 1999. Yeast Dam1p is required to maintain spindle integrity during mitosis and interacts with the Mps1p kinase. Mol Biol Cell 10:2377-91.

Katis VL, Galova M, Rabitsch KP, Gregan J, Nasmyth K. 2004a. Maintenance of cohesin at centromeres after meiosis I in budding yeast requires a kinetochore-associated protein related to MEI-S332. Curr Biol 14:560-72. doi: 10.1016/j.cub.2004.03.001.

Katis VL, Lipp JJ, Imre R, Bogdanova A, Okaz E, Habermann B. 2010. Rec8 phosphorylation by casein kinase 1 and Cdc7-Dbf4 kinase regulates cohesin cleavage by separase during meiosis. Dev Cell 18:397-409. doi: 10.1016/j.devcel.2010.01.014.

Katis VL, Matos J, Mori S, Shirahige K, Zachariae W, Nasmyth K. 2004b. Spo13 facilitates monopolin recruitment to kinetochores and regulates maintenance of centromeric cohesion during yeast meiosis. Curr Biol 14:2183-96. doi: 10.1016/j.cub.2004.12.020.

Keeney S, Giroux CN, Kleckner N. 1997. Meiosis-specific DNA double-strand breaks are catalyzed by Spo11, a member of a widely conserved protein family. Cell 88:375-84. doi: 10.1016/S0092-8674(00)81876-0.

Kerrebrock AW, Moore DP, Wu JS, Orr-Weaver TL. 1995. Mei-S332, a Drosophila protein required for sister-chromatid cohesion, can localize to meiotic centromere regions. Cell 83:247-56.

Kilmartin JV, Adams AE. 1984. Structural rearrangements of tubulin and actin during the cell cycle of the yeast Saccharomyces. J Cell Biol 98:922-33.

Kitajima TS, Kawashima SA, Watanabe Y. 2004. The conserved kinetochore protein shugoshin protects centromeric cohesion during meiosis. Nature 427:510-7. doi: 10.1038/nature02312.

Kitajima TS, Sakuno T, Ishiguro K, lemura S, Natsume T, Kawashima SA. 2006. Shugoshin collaborates with protein phosphatase 2A to protect cohesin. Nature 441:46-52. doi: 10.1038/nature04663.

Laemmli UK. 1970. Cleavage of structural proteins during the assembly of the head of bacteriophage T4. Nature 227:680-5.

Lee BH, Amon A. 2003. Role of Polo-like kinase CDC5 in programming meiosis I chromosome segregation. Science 300:482-6. doi: 10.1126/science.1081846.

Lee BH, Kiburz BM, Amon A. 2004. Spo13 maintains centromeric cohesion and kinetochore coorientation during meiosis I. Curr Biol 14:2168-82. doi: 10.1016/j.cub.2004.12.033.

Lee J, Kitajima TS, Tanno Y, Yoshida K, Morita T, Miyano T. 2008. Unified mode of centromeric protection by shugoshin in mammalian oocytes and somatic cells. Nat Cell Biol 10:42-52. doi: 10.1038/ncb1667.

Longtine MS, McKenzie A III, Demarini DJ, Shah NG, Wach A, Brachat A. 1998. Additional modules for versatile and economical PCR-based gene deletion and modification in Saccharomyces cerevisiae. Yeast 14:953-61. doi: 10.1002/(SICl)1097-0061(199807)14:10<953::AID-YEA293>3.0.CO;2-U.

Marston AL, Amon A. 2004. Meiosis: cell-cycle controls shuffle and deal. Nat Rev Mol Cell Biol 5:983-97. doi: 10.1038/nrm1526. 
Matos J, Lipp JJ, Bogdanova A, Guillot S, Okaz E, Junqueira M. 2008. Dbf4-dependent CDC7 kinase links DNA replication to the segregation of homologous chromosomes in meiosis I. Cell 135:662-78. doi: 10.1016/j. cell.2008.10.026.

Michaelis C, Ciosk R, Nasmyth K. 1997. Cohesins: chromosomal proteins that prevent premature separation of sister chromatids. Cell 91:35-45.

Monje-Casas F, Prabhu VR, Lee BH, Boselli M, Amon A. 2007. Kinetochore orientation during meiosis is controlled by Aurora B and the monopolin complex. Cell 128:477-90. doi: 10.1016/j.cell.2006.12.040.

Morgan DO. 1997. Cyclin-dependent kinases: engines, clocks, and microprocessors. Annu Rev Cell Dev Biol 13:261-91. doi: 10.1146/annurev.cellbio.13.1.261.

Pearson CG, Maddox PS, Salmon ED, Bloom K. 2001. Budding yeast chromosome structure and dynamics during mitosis. J Cell Biol 152:1255-66.

Petronczki M, Matos J, Mori S, Gregan J, Bogdanova A, Schwickart M. 2006. Monopolar attachment of sister kinetochores at meiosis I requires casein kinase 1. Cell 126:1049-64. doi: 10.1016/j.cell.2006.07.029.

Rabitsch KP, Petronczki M, Javerzat JP, Genier S, Chwalla B, Schleiffer A. 2003. Kinetochore recruitment of two nucleolar proteins is required for homolog segregation in meiosis I. Dev Cell 4:535-48.

Riedel CG, Katis VL, Katou Y, Mori S, Itoh T, Helmhart W. 2006. Protein phosphatase 2A protects centromeric sister chromatid cohesion during meiosis I. Nature 441:53-61. doi: 10.1038/nature04664.

Schleiffer A, Kaitna S, Maurer-Stroh S, Glotzer M, Nasmyth K, Eisenhaber F. 2003. Kleisins: a superfamily of bacterial and eukaryotic SMC protein partners. Mol Cell 11:571-5.

Storlazzi A, Xu L, Cao L, Kleckner N. 1995. Crossover and noncrossover recombination during meiosis: timing and pathway relationships. Proc Natl Acad Sci USA 92:8512-6.

Sugimura I, Lilly MA. 2006. Bruno inhibits the expression of mitotic cyclins during the prophase I meiotic arrest of Drosophila oocytes. Dev Cell 10:127-35. doi: 10.1016/j.devcel.2005.10.018.

Sun SC, Zhang DX, Lee SE, Xu YN, Kim NH. 2011. Ndc80 regulates meiotic spindle organization, chromosome alignment, and cell cycle progression in mouse oocytes. Microsc Microanal 17:431-9. doi: 10.1017/ S1431927611000274.

Tanaka TU. 2010. Kinetochore-microtubule interactions: steps towards bi-orientation. EMBO J 29:4070-82. doi: 10.1038/emboj.2010.294

Toth A, Rabitsch KP, Galova M, Schleiffer A, Buonomo SB, Nasmyth K. 2000. Functional genomics identifies monopolin: a kinetochore protein required for segregation of homologs during meiosis i. Cell 103:1155-68.

Towbin H, Staehelin T, Gordon J. 1979. Electrophoretic transfer of proteins from polyacrylamide gels to nitrocellulose sheets: procedure and some applications. Proc Natl Acad Sci USA 76:4350-4.

Tsukahara T, Tanno Y, Watanabe Y. 2010. Phosphorylation of the CPC by Cdk1 promotes chromosome bi-orientation. Nature 467:719-23. doi: 10.1038/nature09390.

Uhlmann F, Lottspeich F, Nasmyth K. 1999. Sister-chromatid separation at anaphase onset is promoted by cleavage of the cohesin subunit Scc1. Nature 400:37-42. doi: 10.1038/21831.

Uhlmann F, Wernic D, Poupart MA, Koonin EV, Nasmyth K. 2000. Cleavage of cohesin by the CD clan protease separin triggers anaphase in yeast. Cell 103:375-86.

Vader G, Blitzblau HG, Tame MA, Falk JE, Curtin L, Hochwagen A. 2011. Protection of repetitive DNA borders from self-induced meiotic instability. Nature 477:115-9. doi: 10.1038/nature10331.

Von Stetina JR, Orr-Weaver TL. 2011. Developmental control of oocyte maturation and egg activation in metazoan models. Cold Spring Harb Perspect Biol 3:a005553. doi: 10.1101/cshperspect.a005553.

Wigge PA, Jensen ON, Holmes S, Soues S, Mann M, Kilmartin JV. 1998. Analysis of the Saccharomyces spindle pole by matrix-assisted laser desorption/ionization (MALDI) mass spectrometry. J Cell Biol 141:967-77.

Xu L, Ajimura M, Padmore R, Klein C, Kleckner N. 1995. NDT80, a meiosis-specific gene required for exit from pachytene in Saccharomyces cerevisiae. Mol Cell Biol 15:6572-81.

Yamamoto A, Hiraoka Y. 2003. Monopolar spindle attachment of sister chromatids is ensured by two distinct mechanisms at the first meiotic division in fission yeast. EMBO J 22:2284-96. doi: 10.1093/emboj/cdg222.

Yamamoto TG, Chikashige Y, Ozoe F, Kawamukai M, Hiraoka Y. 2004. Activation of the pheromone-responsive MAP kinase drives haploid cells to undergo ectopic meiosis with normal telomere clustering and sister chromatid segregation in fission yeast. J Cell Sci 117:3875-86. doi: 10.1242/jcs.01248.

Yu HG, Koshland D. 2005. Chromosome morphogenesis: condensin-dependent cohesin removal during meiosis. Cell 123:397-407. doi: 10.1016/j.cell.2005.09.014. 